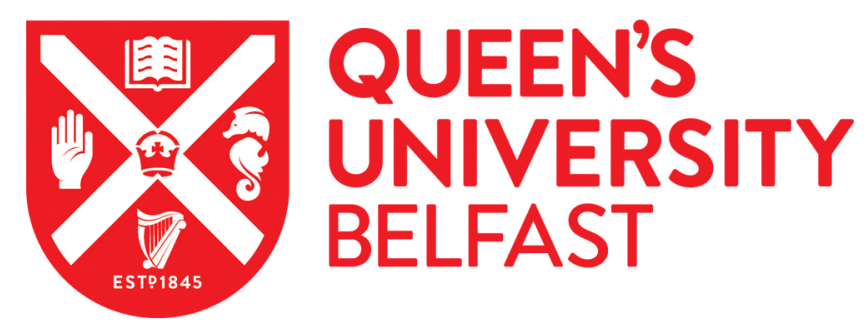

\title{
Effects of motion and structural vibration induced loadings on the coupled dynamic response of a mono-column tension leg platform floating wind turbine
}

Imani, H., Abbaspour, M., Tabeshpoura, M. R., \& Karimirad, M. (2019). Effects of motion and structural vibration induced loadings on the coupled dynamic response of a mono-column tension leg platform floating wind turbine. Proceedings of the Institution of Mechanical Engineers, Part M: Journal of Engineering for the Maritime Environment, 234(2), 426. https://doi.org/10.1177/1475090219882604

Published in:

Proceedings of the Institution of Mechanical Engineers, Part M: Journal of Engineering for the Maritime Environment

Document Version:

Peer reviewed version

Queen's University Belfast - Research Portal:

Link to publication record in Queen's University Belfast Research Portal

Publisher rights

Copyright 2019 SAGE. This work is made available online in accordance with the publisher's policies. Please refer to any applicable terms of use of the publisher.

\section{General rights}

Copyright for the publications made accessible via the Queen's University Belfast Research Portal is retained by the author(s) and / or other copyright owners and it is a condition of accessing these publications that users recognise and abide by the legal requirements associated with these rights.

Take down policy

The Research Portal is Queen's institutional repository that provides access to Queen's research output. Every effort has been made to ensure that content in the Research Portal does not infringe any person's rights, or applicable UK laws. If you discover content in the

Research Portal that you believe breaches copyright or violates any law, please contact openaccess@qub.ac.uk. 
Effects of motion and structural vibration induced loadings on the coupled dynamic response of a mono-column tension leg platform floating wind turbine

\section{Hasan Imani ${ }^{1}$; Madjid Abbaspour²; Mohammad Reza Tabeshpour ${ }^{3}$; Madjid Karimirad ${ }^{4}$}

${ }^{1}$ Ph.D. candidate, Center of Excellence in Hydrodynamics and Dynamics of Marine Vehicles, Department of Mechanical Engineering, Sharif University of Technology, Tehran, Iran.

Email: hasan.imani@mech.sharif.ir

${ }^{2}$ Corresponding author: Professor, Center of Excellence in Hydrodynamics and Dynamics of Marine Vehicles, Department of Mechanical Engineering, Sharif University of Technology, Tehran, Iran.

Email: abbpor@sharif.edu

${ }^{3}$ Assistant professor, Center of Excellence in Hydrodynamics and Dynamics of Marine Vehicles, Department of Mechanical Engineering, Sharif University of Technology, Tehran, Iran. Email: tabeshpour@sharif.edu

\footnotetext{
${ }^{4}$ Associate professor, Civil Engineering, School of Natural and Built Environment, Queen's
} University Belfast, United Kingdom; MIMechE and CEng by Institution of Mechanical Engineers.

Email: madjid.karimirad@qub.ac.uk 


\begin{abstract}
Floating wind turbines (FWTs) are subjected to highly dynamic and complicated environmental conditions leading to significant platform motions and structural vibrations during operation and survival conditions. These motions and vibrations alter the induced loading characteristics and consequently affect the dynamic behaviour of the system. In order to better understand the influence of such motions and structural vibrations, herein elastic structural disturbance of tower, on the system behaviour, the spectral and statistical characteristics of a floating wind turbine dynamic responses under operational and survival conditions are fully explored using a fully-coupled aero-hydro-servo-multi-rigid-flexible-body model (AHS-MRFB). The spectral comparison results showed the important role of aerodynamic damping in reducing the high-frequency resonant responses in operational conditions. These analyses also revealed the effects of tower elasticity in shifting and amplifying high-frequency resonant responses. The statistical comparison results showed that the mean values of the responses are dominated by wind loads and the maximum and standard deviations of the responses are mainly induced by the combination of support platform motions and wave loads. It was also shown that elastic structural deformation of tower enlarges the statistical characteristics of the responses especially when the system is subjected to both wind and wave loadings.
\end{abstract}

Keywords: Offshore wind turbine (OWT), Tension leg platform (TLP), Coupled aero-hydro-servomulti-rigid-flexible-body (AHS-MRFB) analysis, Platform motions, Tower flexibility 


\section{Introduction}

In the last two decades, the offshore wind energy industry has been undergoing a dramatically rapid development as a result of global efforts to reduce greenhouse gas (GHG) emission as well as global demand for energy together with rapid development in the field of wind turbines technology ${ }^{1,2}$. Therefore, various types of bottom-fixed foundations and floating substructures have been proposed as the support structure for coastal and offshore wind turbines. Among them, the bottom-fixed monopile type is the most frequently used foundation form for water regions with depths up to $20 \mathrm{~m}$, while for the depths larger than $30 \mathrm{~m}$ several support structures such as jacket and tripods inspired from the offshore oil and gas industry are the most likely ones to be used ${ }^{3}$. Nevertheless, the exploration of offshore wind energy resources due to preferable generation conditions available in shallow coastal waters is currently the most interest of the industry, though using fixed foundations in much larger depths is not technically feasible and economically viable. On the other hand, the significant amount of wind resources available in water depths greater than $50 \mathrm{~m}$ has led the trend of offshore wind power industry development toward deeper waters $4, \underline{5}$. Moreover, the steadier and more energetic winds, as well as less visual intrusion and noise emissions which lead not only to more electricity generated per square meter of swept rotor area but also larger wind turbines and hence more overall installed capacity per unit area, are another advantages of offshore wind turbines ${ }^{6}$. Consequently, for much deeper regions, exceeding $50 \mathrm{~m}$, the floating support platforms anchored to the seabed by mooring lines system mostly developed based on the offshore oil and gas offshore industry were proposed. Despite the developments have been made regarding the floating offshore wind turbines, various effective technical and numerical simulations supported by experimental tests solutions as well as numerous technological progress in the fields of construction, installation, and maintenance of such foundations are still required ${ }^{4,5}$. Floating support platforms used in offshore wind energy industry are classified differently from bottom-fixed foundations based on the main approach that is used to achieve static stability requirements, i.e., these platforms must provide enough buoyancy and rotational stability to prevent the system from capsizing. Three basic categories based on the contributions of the second moment of the waterplane area, "waterplane (buoyancy) stabilized floating platforms"; the relative position of the center of buoyancy $(\mathrm{CoB})$ and the center of gravity $(\mathrm{CoG})$, "ballast stabilized floating platforms"; and mooring system, "mooring stabilized floating platforms" on fulfilling the stability mechanism are proposed ${ }^{4,7}$. 
Tension Leg Platform (TLP), which relies mainly on tension forces in the pre-tensioned stiff tendons for achieving stability as well as station keeping of system, is one of the concepts which has shown promising results during initial studies to support wind turbines for intermediate (i.e., 45 to $150 \mathrm{~m}$ ) or deep (i.e., more than $150 \mathrm{~m}$ ) waters ${ }^{7-9}$. The challenges with applying such concept in offshore wind farms mostly lie in the complexity with regards to mooring line design which in this case constitute the largest portion of construction cost; installation, maintenance, and decommissioning procedure; possible resonant vibrational controlling devices requirement (i.e., like tuned liquid dampers (TLDs) or tuned mass dampers (TMDs)); and restricted design depth due to the type of mooring system. Such challenges along with advantages of other floating offshore wind turbine (i.e., semi-submersibles and spar-types) in terms of construction cost (i.e., mooring system and installation) and simplicity of installation might lead to a substitution in the planning and design stages $\underline{10}, \underline{11}$. Nevertheless, based on the research studies established on TLPWTs, the limited platform motions of this type of support structure leads to less structural loading on the tower and blades compared to other floating concepts (e.g., spar and semisubmersible) and consequently perform better than the other types ${ }^{9,12}$ without requiring the large draft of a spar or the spread mooring system and complex construction of a semi-submersible. Fully coupled dynamic analyses of Tension Leg Platform (TLP) type FOWT concept in the time and frequency domain have also shown that tension-legged mooring system is stable in both operational and extreme conditions, but needed more improvement in yaw motion which can be improved by increasing the length of the spokes. As a result, this type of floater is likely to provide the most stable and reliable platform compared to other floating concepts, particularly for intermediate waters where other OWT concepts with catenary mooring system are challenging and not feasible ${ }^{7-9}$.

Unlike the bottom-fixed types, the floating-type wind turbines experience a much more complex and strong interaction between aerodynamic and hydrodynamic loadings and system components. This is mainly due to floating configuration and deep water with more severe environmental conditions leading to higher structural loads as well as larger motions/deflections under the combination of wind and wave loads. Such motions and structural vibrations might have significant impacts on the performance of the entire system and individual components. Therefore, the wind turbine system optimum performance highly depends on an accurate modelling of floating wind turbines and environmental loads to estimate the dynamic responses of the turbine 
and support structure correctly $\frac{13}{}$. To this aim, various aero-hydro-servo-elastic numerical models including NREL-FAST, HAWC2, PHATAS, FLEX5, BLADED toolsets, and many others along with real-time integrated/hybrid models have been developed to predict the accurate response of an OWT system dynamic behaviour under different environmental conditions and system

Many studies have been carried out for load and response estimation of offshore wind turbines with different support structures in the recent years. These studies were mainly concentrated on dynamic time-domain simulation of different foundations under uncoupled or combined wind and wave conditions from a given environmental conditions in normal and extreme operating conditions $\frac{9,15-17}{}$. Withee and Sclavounos (2004) $)^{\frac{18}{}}$ and Wayman, et al. (2006) $)^{\frac{19}{9}}$ developed and performed a fully coupled time-domain method to evaluate the effects of wind and wave loads in normal and extreme operating conditions on a 1.5-MW tension leg platform wind turbine. The numerical simulations results compared to the land-based turbine showed that platform motions have considerable effects on power production and rotor loads as well as on the nacelle and tower loads which could lead to less fatigue life. It was also indicated that the effects of loads on turbine components in operational conditions would be higher than the parked conditions. The same results were obtained by Zhao, et al. (2016) ${ }^{20}$ who studied the global performance of a multicolumn tension leg type wind turbine (i.e., WindStar TLP system) in comparison with a land-based system employing a similar turbine under normal and parked conditions using NREL-FAST toolset. It has been found that the out-of-plane blade deflection and nacelle surge acceleration of the floating wind turbine are larger than the land-based system. In addition, Matha (2009) 9 , Karimirad and Moan (2010) $)^{21}$, Bae et al. (2013) ${ }^{22}$, Bachynski, et al. (2014) $(2017)^{23}$ also pointed out the importance of interaction between tower flexibility and platform motion in the analysis of natural frequencies, aerodynamic excitations, and damping of tension leg platform wind turbines. Moreover, Bae et al. (2013) $\frac{22}{2}$ investigated the effects of the rotor-floater dynamic in addition to the mooring-floater dynamic coupling through a rotor-floater-tether coupled dynamic analysis on a mini TLP-type offshore floating wind turbine. The comparison results with the uncoupled case showed that considering the rotor-floater coupling causes more pronounced loads and responses especially at high frequencies which has implications on maximum-stress and fatigue life design. 
Even though there have been many researches on dynamic analysis of FOWT systems in recent years, the fully-coupled aero-hydro-servo-multi-rigid-flexible-body (AHS-MRFB) dynamic behaviour characteristics of a FOWT under different environmental conditions with various loading scenarios and different control strategies have not been fully explored. Accordingly, in the present study, the importance and principles of coupling effects between the external loadings, controlling approaches, motions, and structural flexibility, herein tower flexibility, on the power performance, structural integrity, and overall dynamic motion and mooring line responses of a mono-column full-scale three-bladed tension-leg-platform floating wind turbine are comprehensively evaluated. To this aim, the dynamic performance of the MIT/NREL TLP floating wind turbine concept under stochastic aerodynamic and hydrodynamic loads is evaluated through a series of time-domain dynamic coupled simulations using the fully coupled aero-servo-hydromulti-rigid-flexible-body (AHS-MRFB) model, NREL-FAST toolset. The spectral and statistical dynamic response characteristics of the TLP model is then carried out for three loading scenarios (i.e., wind-induced only, wave-induced only as well as combined actions of wind and wave) with various operational and extreme environmental conditions to evaluate the changes affected by aforementioned key factors on system dynamic behaviour in all possible loading conditions. The current work will give an insight into the dynamic performance of a hypothetical 5MW TLPOWT concept which could result in a comprehensive understanding of such concept and present a better interpretation for future modifications to the initial design for designers in the field of offshore wind industry as well as design standards.

\section{Configuration of MIT/NREL TLP wind turbine}

\subsection{Wind turbine properties}

The wind turbine model used in this study is the NREL 5-MW offshore baseline wind turbine supported by a tension leg platform foundation. This model is a three-bladed upwind 5-MW wind turbine with a variable-blade-pitch-to-feather control system. The control system in this model uses a conventional control approach in which a generator-torque controller utilized in order to maximise captured power below the rated wind speed and a blade-pitch controller to minimise the drivetrain load by regulating rotor speed above the rated wind speed. The detailed specifications and dimension properties of 5MW turbine based on global coordinate system presented in Figure 1 are described in Table 1. 
Table 1. Main properties of the NREL 5-MW baseline wind turbine ${ }^{9}$.

\begin{tabular}{|c|c|c|}
\hline Characteristics & & Value \\
\hline Power & & $5 \mathrm{MW}$ \\
\hline Rotor orientation, configuration & & Upwind, 3 Blades \\
\hline Control strategy & & Variable speed, collective pitch \\
\hline Cut-in, rated, cut-out wind speed & & $3 \mathrm{~m} / \mathrm{s}, 11.4 \mathrm{~m} / \mathrm{s}, 25 \mathrm{~m} / \mathrm{s}$ \\
\hline Cut-in, rated rotor speed & & $6.9 \mathrm{rpm}, 12.1 \mathrm{rpm}$ \\
\hline \multirow{5}{*}{ Rotor Nacelle Assembly (RNA) } & Hub height & $90 \mathrm{~m}$ \\
\hline & Rotor, hub diameter & $126 \mathrm{~m}, 3 \mathrm{~m}$ \\
\hline & Rotor mass & $110,000 \mathrm{~kg}$ \\
\hline & Nacelle mass & $240,000 \mathrm{~kg}$ \\
\hline & C.G. location & $(-0.414,0,89.57) \mathrm{m}$ \\
\hline \multirow{5}{*}{ Tower } & Mass & $347,460 \mathrm{~kg}$ \\
\hline & Height & $87.6 \mathrm{~m}$ \\
\hline & Diameter (top) & $3.87 \mathrm{~m}$ \\
\hline & Diameter (base) & $6 \mathrm{~m}$ \\
\hline & C.G. location & $(0,0,38.234) \mathrm{m}$ \\
\hline \multirow{2}{*}{ Overall (Tower \& RNA) } & Mass & $697,460 \mathrm{~kg}$ \\
\hline & C.G. location & $(-0.2,0,64) \mathrm{m}$ \\
\hline
\end{tabular}

It is to be noted that current edition of the International Electrotechnical Commission (IEC) design standard as the preeminent design code for offshore wind turbines recommends $1 \%$ of critical for structural damping without making any distinction between the required values for foreaft or side-to-side directions $\underline{24}, \underline{25}$. The recent experimental and numerical studies on various source of damping in offshore wind turbines have also shown $0.5-1.5 \%$ of critical damping for tower and $0.5 \%$ of critical damping for the blades ${ }^{26}$. Therefore, in the present study, the structural damping ratios of $1 \%$ and $0.5 \%$ are applied to all modes of tower and blades in the related analyses, respectively, which are also consistent with the definition of the NREL 5 MW structure ${ }^{27}$.

\subsection{Platform and mooring system properties}

The MIT/NREL tension-leg-platform is a positively buoyant structure consisting of a main steel cylindrical platform, ballasted with concrete and water which support the vertical tower with the nacelle and the rotor. It also has four radiating spokes that extend horizontally from the bottom of the platform in which the tension-legged mooring cables (four pairs of pretension vertical tendons) are connected at the end of each spoke and anchored to the seabed (see Figure 1). The tension legs compensate the force difference between the total structural weight and water displacement which in this case leads to a ratio of $24 \%$ between the total tension in legs and the 

Table 2 according to global coordinate system presented Figure 1.

Table 2. Properties for the floating platform and mooring system .

\begin{tabular}{ll}
\hline Characteristics & Value \\
\hline Diameter & $18 \mathrm{~m}$ \\
Draft & $47.89 \mathrm{~m}$ \\
Water displacement & $12,187,000 \mathrm{~kg}$ \\
Mass, including ballast & $8,600,041 \mathrm{~kg}$ \\
Concrete mass & $8,216,000 \mathrm{~kg}$ \\
Concrete height & $12.6 \mathrm{~m}$ \\
CoM location below still water level (SWL) & $40.612 \mathrm{~m}$ \\
CoB location below still water level (SWL) & $23.945 \mathrm{~m}$ \\
Roll inertia about CM & $571.6 \times 10^{6} \mathrm{~kg} \cdot \mathrm{m}^{2}$ \\
Pitch inertia about CM & $571.6 \times 10^{6} \mathrm{~kg} \cdot \mathrm{m}^{2}$ \\
Yaw inertia about CM & $361.4 \times 10^{6} \mathrm{~kg} \cdot \mathrm{m}^{2}$ \\
Steel wall thickness & $0.015 \mathrm{~m}$ \\
Average steel density & $7850 \mathrm{~kg} / \mathrm{m}^{3}$ \\
Average concrete density & $2562.5 \mathrm{~kg} / \mathrm{m}^{3}$ \\
Number of mooring lines & 8 \\
Depth to fairleads, anchors & $47.89 \mathrm{~m}, 200 \mathrm{~m}$ \\
Radius to fairleads, anchors & $27 \mathrm{~m}, 27 \mathrm{~m}$ \\
Unstretched line length & $151.73 \mathrm{~m}$ \\
Line diameter & $0.127 \mathrm{~m}$ \\
Average mooring system tension per line & $3931 \mathrm{KN}$ \\
Line mass density & $116.03 \mathrm{~kg} / \mathrm{m}$ \\
Line extensional stiffness & $1.5 \times 10^{9} \mathrm{~N}$ \\
\hline
\end{tabular}

\subsection{Wind turbine and platform combined}

The combined system of the wind turbine and platform results in a new mass, C.G., and inertia of the system. Table 3 gives the properties of the assembly of the MIT/NREL TLP and NREL$5 \mathrm{WW}$ wind turbine (see Figure 1). It is to be stated that the full system properties for this TLPWT are very limited and unclear in the existing literature; and therefore, presented values are carefully derived from detailed C.G. and mass moment of inertia of the various components of the system using Steiner's Rule $\underline{28}$. 
Table 3. Summary of mass, C.G., C.B., and moment inertia of the system from different resources.

\begin{tabular}{ll}
\hline Turbine properties & Value \\
\hline System mass & $9,297,460 \mathrm{~kg}$ \\
Center of mass & $(-0.015,0,-32.7644) \mathrm{m}$ \\
Center of buoyancy & $(0,0,-23.94) \mathrm{m}$ \\
Inertia around x-axis & $9.07 \times 10^{9} \mathrm{~kg} \cdot \mathrm{m}^{2}$ \\
Inertia around y-axis & $9.05 \times 10^{9} \mathrm{~kg} \cdot \mathrm{m}^{2}$ \\
Inertia around z-axis & $6.06 \times 10^{8} \mathrm{~kg} \cdot \mathrm{m}^{2}$ \\
\hline
\end{tabular}

It is to be noted that the presented properties for each component along with overall characteristics of wind turbine system in this section as well as environmental loading directions to be utilized in further numerical analysis are based on the global coordinate system shown in Figure 1. The origin of this coordinate system is taken as the xy-plane at the intersection of the undisplaced platform centerline and mean sea level (MSL). The z-axis is also chosen to be upward and perpendicular to the xy-plane.

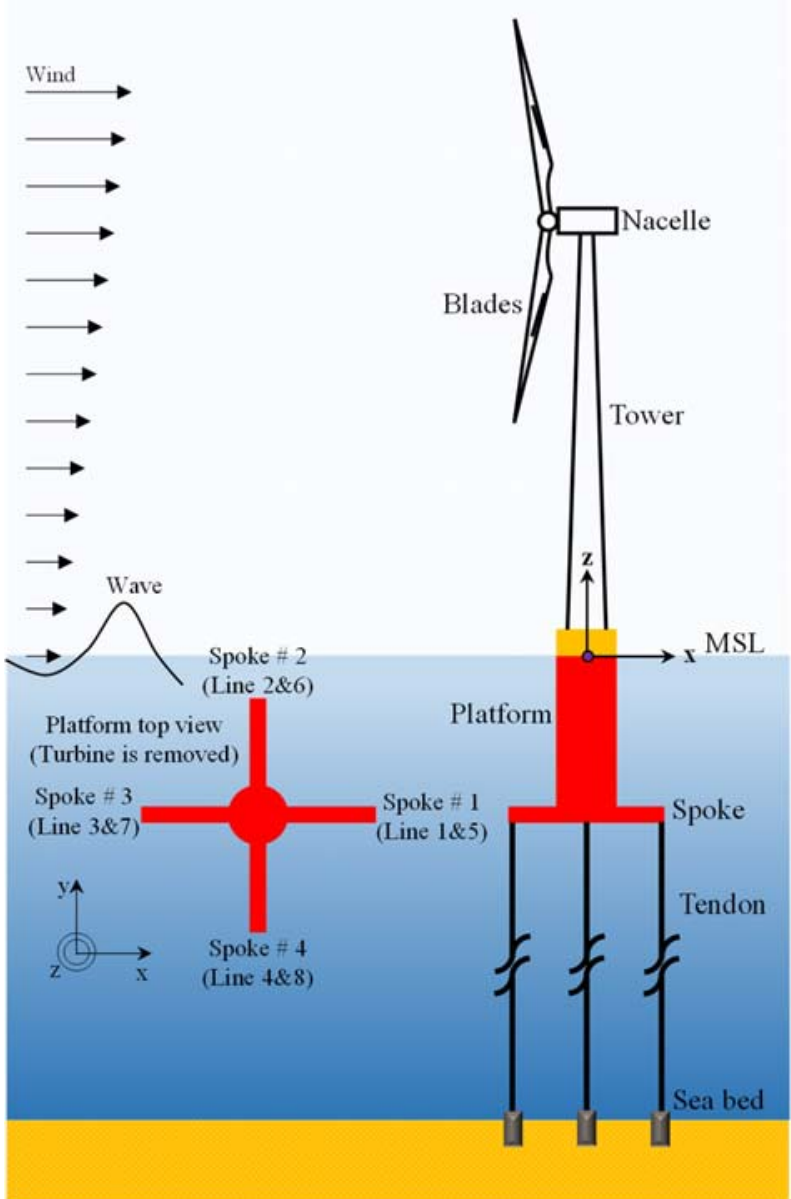

Figure 1. MIT/NREL TLPWT system layout and utilized global coordinate system showing the directions of translational and rotational oscillatory motions as well as environmental loadings. 


\section{Coupled aero-hydro-servo-multi-rigid-flexible numerical model}

The fully coupled time-domain analysis of the mono-column tension-leg-platform floating three bladed horizontal-axis wind turbine (i.e., MIT/NREL 5-MW tension-leg-platform) is carried out using the coupled aero-hydro-servo-multi-rigid-flexible time-domain simulator code, NRELFAST (Fatigue, Aerodynamics, Structures, and Turbulence). This model integrates several physical-based modules (i.e., AeroDyn, HydroDyn, ServoDyn and ElastDyn) through a combined modal and multibody system dynamics with limited degree of freedom (DOF), meaning that the aerodynamic (aero), hydrodynamic (hydro), control system (servo), and structural-dynamic (elastic) models incorporate in a fully coupled (integrated) simulation environment to account the coupling between wind turbine and support platform dynamics $\underline{29}$. In the AeroDyn $\underline{30}$ module, the generalized dynamic wake (GDW) model and blade element momentum (BEM) theory modified by multiple correction factors and models are used to compute aerodynamic loads and rotor wake effects on the rotor-nacelle-assembly (RNA). In HydroDyn $\frac{31}{}$, the hydrodynamic forces and moments acting on the support structure considering the hydrostatic restoring loads, effects of added mass, and nonlinear viscous drag contributions are calculated based on Airy wave theory using a prescribed wave spectrum. In ServoDyn module, the rotor-nacelle-assembly (RNA) electrical derived subcomponents such as blade pitch angle, generator torque, nacelle yaw angle, high-speed shaft and blade tip brakes, are controlled under a schemed stable operational configuration through a dynamic link library (DLL) or a MATLAB/Simulink interface. In ElastDyn, the controller reactions and calculated environmental loadings on the system along with the gravitational forces are incorporated into a multi-rigid-flexible-body (MRFB) structural dynamic model of the system to solve the governing equation of motion and analyze the dynamic structural responses of the system components. The resulting dynamics (i.e., displacement, velocities, accelerations, and reaction loads) at each time step are exchanged as inputs between different modules of the toolset. Figure 2 presents a detailed overview of the NREL-FAST structure including the various modules making up the main toolset along with input and output datasets of analysis process between different modules. Further details regarding models and dynamic formulations are given in NREL-FAST user manual 29 . This procedure without any changes or improvements in the original codes is used in the present study (see Figure 2). 


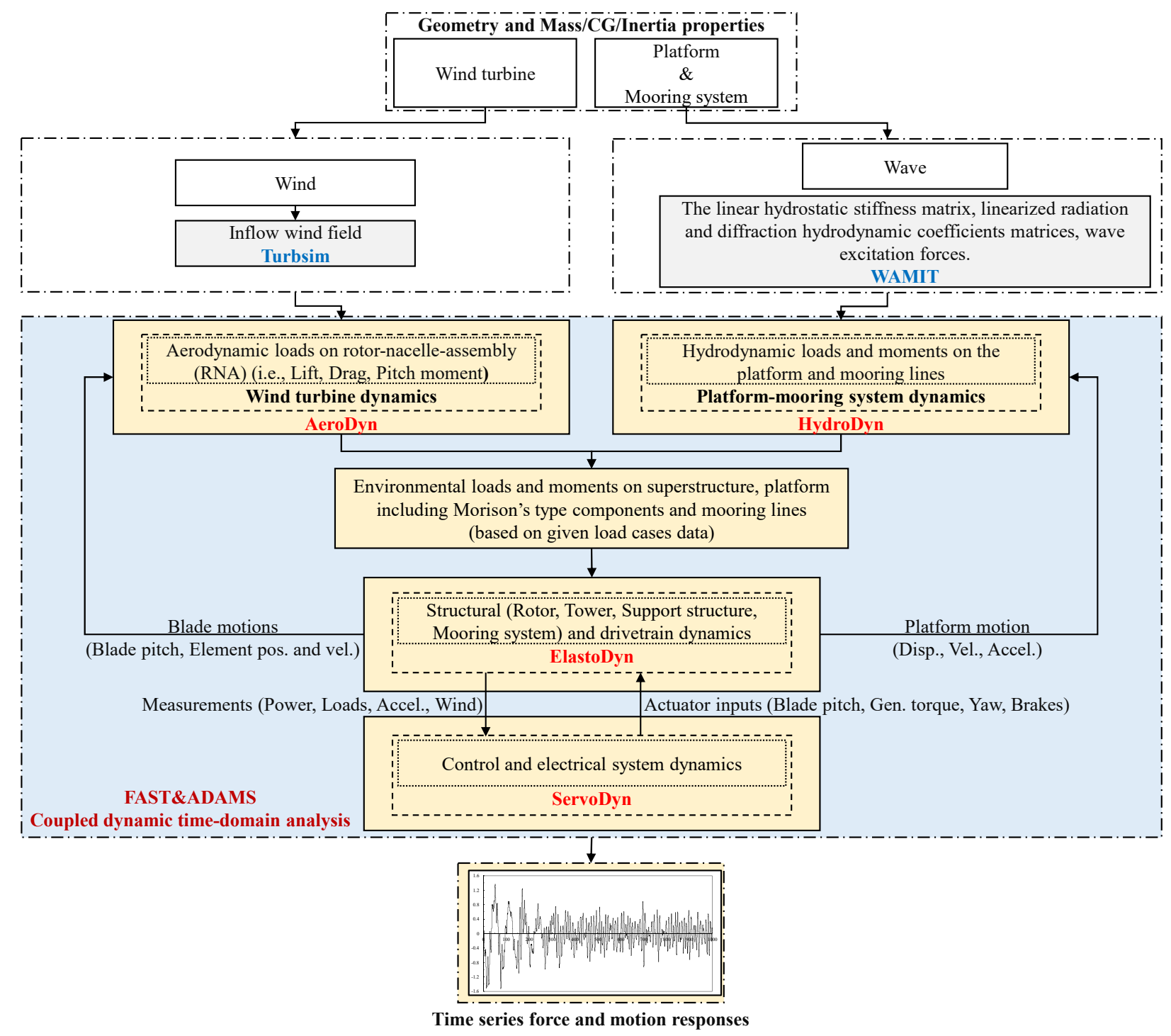

Figure 2. Graphical procedure of coupled dynamic time-domain analysis in NREL-FAST toolset.

\subsection{Equation of motion}

Floating offshore wind turbines experience complex loading conditions under different environmental phenomena. Accordingly, a time-domain aero-hydro-servo-elastic analysis which considers the non-linearities, irregularity and coupling effects, as well as complexity of both the dynamic external loads and the structure, is required in order to ensure structural safety of all components under different conditions by determining the most accurate response of the offshore wind turbine. The fully-coupled nonlinear dynamic aeroelastic time-domain governing equation of motion for floating offshore wind turbine can be written as follows: 


$$
M_{i, j}(\eta, u, t) d^{2} \eta_{j} / d^{2} t+F_{i}(\eta, d \eta / d t, u, t)=0
$$

In equation (1), the first term of the equation represents the coupled system inertia forces originating from the platform, tower, nacelle, hub, and blades masses in which, $M_{i, j}$ is the $(i, j)^{\text {th }}$ component of the inertia mass matrix of the system depending on a nonlinear combination of the system displacement $\eta$, wind turbine control input $u$, and time $t ; d^{2} \eta_{j} / d^{2} t$ is the second time derivative of the $j^{\text {th }}$ component of degree of freedoms. The second term of the equation $F_{i}$ is the $i^{\text {th }}$ component of the forcing function (i.e., aerodynamic and hydrodynamic forces on floating platform and mooring cables) depending on a nonlinear combination of system displacement and velocity $\eta$ and $d \eta / d t$, wind turbine control input $u$, and time $t$. The key elements of governing equation including loading and structural numerical modelling are shortly described in the following sub-sections for the sake of clarity and brevity.

\subsection{Aerodynamic loads on the wind turbine}

Interaction of wind turbine structure with the wind field results in aerodynamic loads on the entire wind turbine system. During the last few decades, several approaches have been introduced to estimate aerodynamic loads on wind turbines. The most comprehensive numerical methods are using computational fluid dynamics (CFD) based on solving the Navier-Stokes (NS) equations. Nevertheless, since these methods are very time consuming, other models which are less complex and time-consuming such as the advanced blade element momentum (ABEM) theory (with correction equations such as Prandtl's tip loss factor, Spera's correction, and the Du-Selig stall delay model) and the generalized dynamic wake (GDW) model have been widely used to estimate the resulting aerodynamic forces acting on wind turbine blades. Possible advantages of GDW model over basic blade element momentum (BBEM) theory include a more efficient performance and inherent capability to model dynamic inflow effects as a result of changes in the blade angles of attack or wind speed relative to the rotor, tip losses, and skewed wake aerodynamics. Nevertheless, this model is not only unstable for low wind speed but also cannot determine the tangential induction effects on the blades. Therefore, the aerodynamic module of NREL-FAST toolset, i.e., AeroDyn ${ }^{30}$, calculates the aerodynamic loads and rotor wake effects on the rotornacelle-assembly (RNA) using ABEM theory for low wind speeds (i.e., less than $8 \mathrm{~m} / \mathrm{s}$ ) and a combination of ABEM theory and GDW model for higher wind speeds to overcome the limitations 
in each method. For the sake of clarity and completeness, readers are referred to AeroDyn $\underline{\underline{30}}$ and NREL-FAST $\stackrel{29}{ }$ user manuals for more details related to aerodynamic loading calculation methodology.

\subsection{Hydrodynamic loads on the floating support platform}

Hydrodynamic loads on floating offshore wind turbine systems result from the integration of the dynamic pressure of the water over the wetted surface of the support platform include contributions from linear hydrostatics, linear excitation from incident waves in regular or irregular seas (Froude-Krylov), incident wave scattering (diffraction), linear radiation including the freesurface memory effects, and nonlinear effects (i.e., viscous drag from incident-wave kinematics and the platform motion, second-order and higher-order excitations). In the present study, the hydrodynamic module of NREL-FAST toolset, HydroDyn $\underline{31}$ is used to calculate the hydrodynamic forces and moments on the support platform. Based on this module, the total hydrodynamic loads acting on the floating support platform are considered as the sum of hydrostatic loads; first-order wave loads, and nonlinear viscous drag loads and the mooring system reactions on spokes. The first-order wave excitation forces and moments acting on the floating platform considering the relative fluid velocity vector between the flow and the body are predicted using the linear potential flow theory by assuming that the wave amplitude and body motion are small. The quadratic viscous excitation drag forces per unit length acting on the structural components that are slender compared to the wavelength (e.g., spokes) caused by relative velocity to the structure movement are also evaluated using the Morison's equation. The restoring forces from the tension mooring system at the fairleads are approximated by a multi-segmented, nonlinear quasi-static solver through the pretension loads from excess buoyancy including the contribution of the weight of the cable in water and the linearized restoring stiffness of the mooring lines due to the elastic characteristics, the apparent weight of the tendons in water, and the nonlinear geometric restoration of the entire mooring system. The tendons in this model are assumed to remain straight disregarding changes in buoyancy (i.e., linearity) and the bending stiffness, inertia, and damping of the mooring lines are neglected $\frac{15}{5}$. In this paper for the sake of brevity, the details regarding hydrodynamic modelling and formulations are not provided in the text; nevertheless, readers are referred to HydroDyn $\frac{31}{}$ and NREL-FAST $\stackrel{29}{ }$ user manuals for more detailed information. 


\subsection{Structural modelling}

The multi-rigid-flexible-body model (MRFB) of the structure in NREL-FAST toolset is defined through 24 DOFs for multiple components of a three-bladed FOWT (see Equation 1). The main elastic structural components considered in the MRFB model are the tower and blades. The flexibility of both structures is implemented in the model by the normal mode shape summation method considering three vibrational modes for each blade (i.e., two first flapwise modes and one edgewise mode) and two vibrational modes for tower (i.e., fore-aft and side-to-side modes). These components are both modelled as cantilevered beams being fixed at one end and free at the other end, in which the fixed end boundary conditions/DOFs of tower, i.e., tower-base boundary conditions, are influenced by platform motions and mooring system interactions affecting the tower structural vibrations in both modes. Accordingly, the vibrational reactions of the tower at each node is determined by the combined motion of the platform and tower-bending degrees of freedom (DOFs). In this paper for the sake of brevity, details regarding nonlinear MRFB dynamics of the structure are not described and readers are referred to NREL-FAST user manual $\stackrel{29}{ }$ for more information.

\section{Validation of numerical model of system}

In order to validate the floating offshore wind turbines input specifications and verify the accuracy of responses carried out by NREL-FAST, first, a set of numerical free vibration simulations in time domain were carried out and the natural frequencies of rigid body motions of the MIT/NREL TLP wind turbine were calculated. The values of natural frequencies are given in Table 4. From Table 4, it is clear that the natural frequencies are in reasonable agreement with values from NREL ${ }^{-}$, it is consequently assumed that the values in the mass and stiffness matrix calculated in the FAST model based on the floating offshore wind turbine input specifications are correct.

Table 4. Natural frequencies of the MIT/NREL TLP system.

\begin{tabular}{lll}
\hline \multirow{2}{*}{\multicolumn{1}{c}{ Mode }} & \multicolumn{2}{c}{ Natural frequency $(\mathrm{rad} / \mathrm{sec})$} \\
\cline { 2 - 3 } & NREL & FAST \\
\hline Platform surge/sway & 0.1037 & 0.0942 \\
Platform heave & 2.7489 & 2.7439 \\
Platform roll & 1.4005 & 1.3961 \\
Platform pitch & 1.3892 & 1.3961 \\
Platform yaw & 0.6107 & 0.6176 \\
\hline
\end{tabular}


Then, the pitch motion response obtained in the present study is compared for the same TLP and environmental loading as modelled by Matha $(2009)^{9}$ with the following load case; a significant wave height of $4.4 \mathrm{~m}$ at a peak spectral period of 11.3 second with a hub-height constant wind speed of $20 \mathrm{~m} / \mathrm{s}$. The maximum and minimum pitch angles responses in the reference study are $0.68 \mathrm{deg}$ and $-0.48 \mathrm{deg}$, respectively. The results of the simulation with the current model show a maximum and minimum of $0.524 \mathrm{deg}$ and $-0.445 \mathrm{deg}$. Therefore, according to the good agreement achieved in the free vibration analysis and statistical comparison performed for a sample load case, it can be concluded that the MIT/NREL TLPWT model established in the NRELFAST toolset is capable of predicting the frequency- and time-domain responses of the system with sufficient degree of accuracy.

\section{Environmental conditions}

The most important meteorological and oceanographic data for a floating wind turbine is the wind and wave conditions. Wind and wave climates are correlated because, in an offshore site, the ocean waves are mostly wind-generated waves. Therefore, for design purposes, it is recommended to consider the correlation between wind and waves for stochastic analysis of FWTs. Accordingly, in the present study, a wind-wave joint probabilistic model based on the Northern Sea environmental conditions proposed by Johannessen et al. (2001) $)^{32}$ is used (see Figures 3 and 4). Based on this model, an estimation of the sea-states can be provided by using a given hub height mean wind speed, $V$, the marginal distribution of the $1-\mathrm{h}$ mean wind speed at $10 \mathrm{~m}$ above the mean sea level, the expected value of the significant wave height, $H_{s}$, described by two-parameter Weibull distributions and a log-normal distribution for the spectral peak period, $T_{p}$, as described in equations (2), (3) and (4):

$$
\begin{aligned}
& F(V)=1-\exp \left[-(V / \beta)^{\alpha}\right] \\
& E\left(H_{s}\right)=\beta_{H_{s}} \Gamma\left(1+1 / \alpha_{H_{s}}\right) \\
& E\left(T_{p}\right)=\left(4.833+2.68 H_{s}^{0.529}\right)\left[1-0.19\left[\frac{V-\left(1.764+3.426 H_{s}^{0.78}\right)}{1.764+3.426 H_{s}^{0.78}}\right]\right]
\end{aligned}
$$

where $\alpha=1.708, \beta=8.426, \alpha_{H_{s}}=2+0.135 V$ and $\beta_{H_{s}}=1.8+0.1 V^{1.322}$ are the proposed marginal and conditional shape and scale parameters for wind speed and significant wave height distributions, respectively. 
The cut-in and cut-out wind velocities of the MIT/NREL 5MW TLP wind turbine are $3 \mathrm{~m} / \mathrm{s}$ and $25 \mathrm{~m} / \mathrm{s}$, respectively. For the present study, first, different wind speeds within the range of the operating and parked conditions are chosen to define the sea state conditions. Then, by using these selected wind speeds, the values of $H_{s}$ and $T_{p}$ are estimated using the analytical functions given in equations (2), (3) and (4). Table 5 shows the estimated environmental conditions. The obtained environmental load cases are afterwards implemented into the aero-hydro-servo-elastic tool NREL-FAST considering three different loading combinations: wave-induced only, wind-induced only, and combined wind and wave loading with two parked and rotating rotor configurations, in order to assess different aspects and performance of the floating TLP wind turbine system.

Table 5. Selected load cases for operational and survival conditions.

\begin{tabular}{llllll}
\hline Load cases & $V(\mathrm{~m} / \mathrm{sec})^{*}$ & $H_{s}(\mathrm{~m})$ & $T_{p}(\mathrm{sec})$ & Turbulence & Turbine status \\
\hline 1 & 8.0 & 2.5 & 9.8 & 0.18 & Operating \\
2 & 11.2 & 3 & 10 & 0.15 & Operating \\
3 & 14 & 3.6 & 10.2 & 0.15 & Operating \\
4 & 17 & 4.2 & 10.5 & 0.15 & Operating \\
5 & 25 & 5.9 & 11.3 & 0.12 & Parked \\
6 & 30 & 7.1 & 11.9 & 0.11 & Parked \\
\hline
\end{tabular}

${ }^{*}$ The 10 -min averaged wind speed at the nacelle.

The 10-min mean wind speeds at the nacelle listed in Table 5 are estimated by scaling up the 1-hour mean wind speed at $10 \mathrm{~m}$ above the still water level by a factor of $10 \%$. Then, the 10 -min mean wind speed at the reference height (10-m) above the water level, $V_{\text {ref }}$, is transformed into the 10-min mean wind speed at the hub height at $90-\mathrm{m}, \mathrm{V}$, using the widely used power law-wind shear model given as in equation (5) developed for neutral atmospheric conditions is used.

$$
V(z)=V_{\text {ref }}\left(z / z_{\text {ref }}\right)^{\alpha}
$$

where, $z$ is the height above still water level and $z_{\text {ref }}$ is the reference height. The power law exponent of 0.12 has been used for the ocean surface $\frac{33}{\text {. }}$.

Turbulence refers to natural fluctuations in wind speed (i.e. standard deviation of mean wind speed) about the mean wind speed. The turbulence intensity is a basic measure of turbulence and is defined as the variance of wind velocity over the mean wind speed during a relatively fast timescale (i.e. 10-minute period) (see equation (6)).

$$
T_{I}=\sigma_{V} / V_{\text {ref }}
$$


where, $T_{I}$ is turbulence intensity, $\sigma_{V}$ is standard deviation and $V_{\text {ref }}$ is mean wind speed at reference height which usually is defined 10 meters above mean sea level. The mean value of the wind speed standard deviation can be estimated through the following equations:

$$
\begin{aligned}
& E\left[\sigma_{V}\right]=V_{r e f} A_{x} k_{a} / \ln z / z_{0} \\
& A_{x}=\sqrt{1.5-0.856 \ln z_{0}}
\end{aligned}
$$

In which, $A_{x}$ is a constant dependent on $z_{0}, k_{a}$ is the von Karman's constant (0.4) and $z_{0}$ is the roughness length which depends on wind speed, upstream distance to land, water depth and wave field for offshore sites. The value of the roughness parameter for offshore locations varies between 0.0001

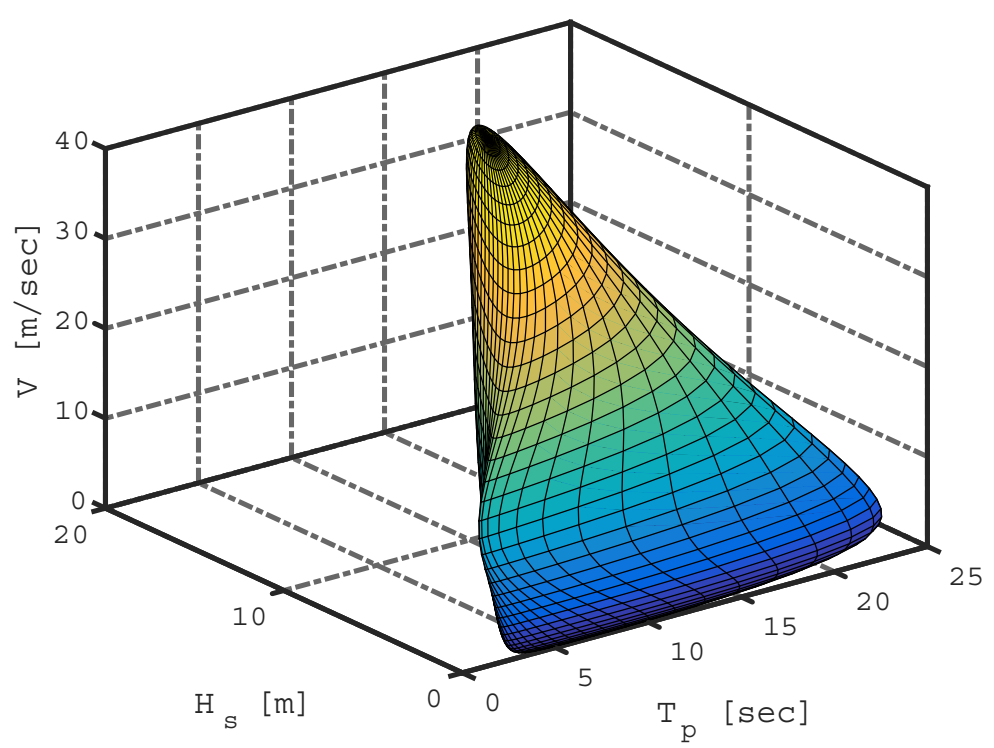

Figure 3. 100-year mean return period (MRP) contour surface of the met-ocean variables for North 416 Sea $a^{32}$. 


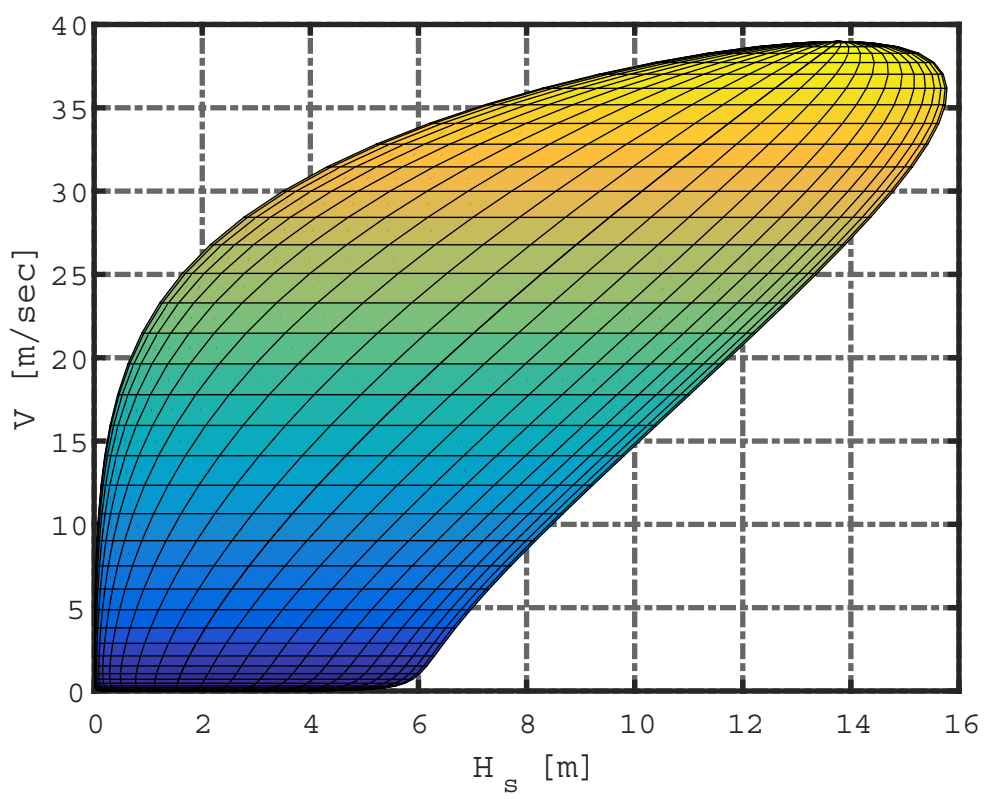

Figure 4. 100-year mean return period (MRP) contour lines of the mean wind speed verses significant wave height for North $\mathrm{Sea}^{32}$.

\section{Operational and survival mode controlling strategies}

The wind turbine system performance and response (power, speed, etc.) are typically dictated by the control system. The control system behaviour itself depends on wind speed, as shown in Figure 5. Therefore, it is essential to have a good understanding of the turbine's status in operational and survival conditions in order to apply the proper setting in the numerical simulations

The NREL 5-MW baseline wind turbine model uses a variable-speed, collective pitch controller system for controlling power-production. The variable-speed controller uses generator speed and hence generator torque to control rotor speed and maximise the power extraction at values between the cut-in $(3 \mathrm{~m} / \mathrm{s})$ and rated wind velocity $(11.4 \mathrm{~m} / \mathrm{s})$. Accordingly, to analyze the wind turbine system in operational modes under the rated wind speed, the variable-speed controller should be activated. At wind speeds above the rated wind velocity, the collective blade pitch controller controls the blade pitch angle to minimise the aerodynamic loads on the blades. It also regulates generator speed and hence generator torque above the rated wind velocity in order to have a constant power output. Consequently, the collective blade pitch controller should be activated between rated and cut-out wind speed. 
In the operational conditions, the wind turbine normally functions and generates electricity under the action of the control system. The tip brake and high-speed shaft (HSS) brake are also not applied for this condition during the entire simulation time. On the contrary, during extreme environmental conditions when the turbine is parked, the functionality of the turbine is totally shut down and the turbine does not generate electricity. The rotor and shafts of the wind turbine are locked down to prevent damage to the structural components of the turbine and none of the abovementioned control strategies are needed to be applied. Figure 5 illustrates the NREL 5-MW wind turbine's steady-state responses with respect to wind speed 15 .

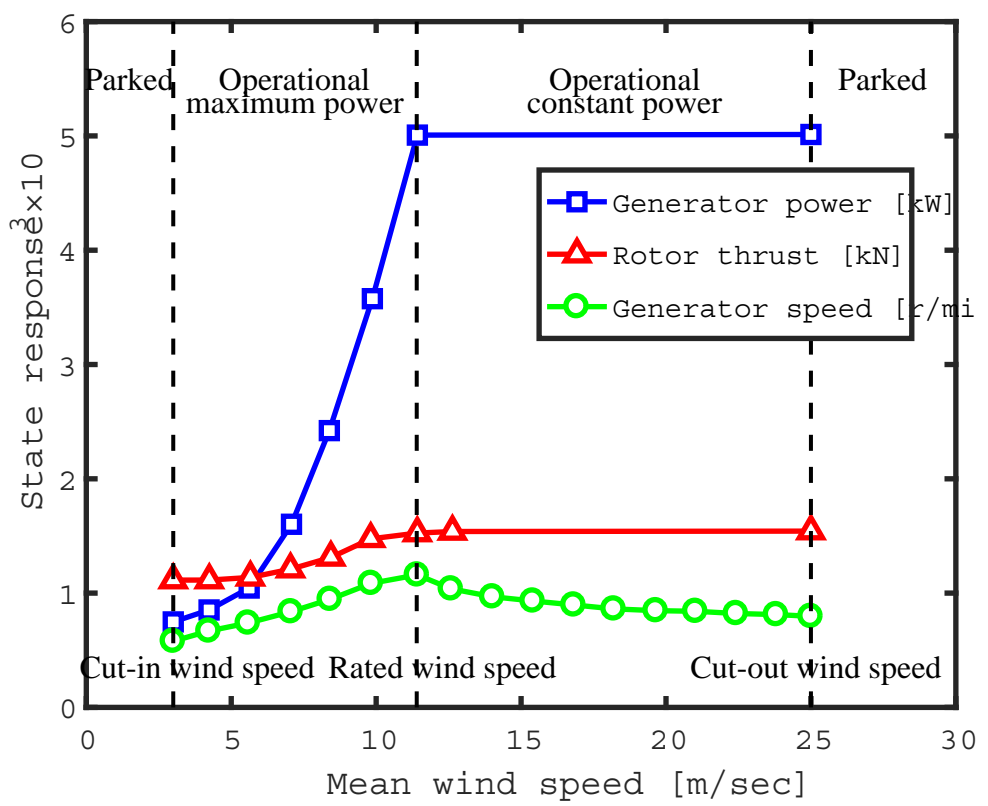

Figure 5. Steady state response of the NREL 5MW wind turbine ${ }^{15}$.

\section{Simulation set-up specifications}

In Addition to the generally aforementioned controlling strategies for simulation in different load cases and combinations, it should be noted that regarding the loading status considered in the present study (i.e., simulations under wave-induced only, wind-induced only, and coupled windwave loading), proper settings and changes also should be specified in the numerical simulations. To analyze the wind turbine system in still air conditions (i.e., wind speed $=0 \mathrm{~m} / \mathrm{s}$ ), the aerodynamic loads and dynamic inflow wake calculations within AeroDyn module through the entire load cases presented in Table 5 are disabled and the whole system is subjected only to unidirectional irregular wave excitations prescribed by JONSWAP wave spectrum. To analyze the wind turbine in still water conditions (i.e., wind-induced only load cases), on the other hand, 
hydrodynamic force computation on floater and mooring system within HydroDyn module of NREL-FAST toolset are disabled and aforementioned controlling strategies with respect to the wind speed as well as aerodynamic loads and dynamic inflow effects are enabled. The required stochastic wind turbulence fields corresponding to the hub-height mean wind speed defined in Table 5 were generated using TurbSim ${ }^{34}$, a stochastic, full-field, turbulent-wind simulator developed by NREL. In this regard, a turbulent box with a grid size of 145 times 145 meters centered horizontally at hub height position (i.e., $19 \mathrm{~m}$ below assuming the top of the grid is aligned with the top of the rotor disk and $9.5 \mathrm{~m}$ on each side) is chosen to ensure that the grid box is large enough to cover the entire rotor disk with an additional safety space accounting for maximum expected value of the system motions and structural displacements estimated based on a set of trial simulations as well as an extra safety factor of $10 \%$ according to the TurbSim guideline. This is due to the fact that AeroDyn module does not allow any part of the blade including all system motions and displacements to lie outside of the generated wind grid by TurbSim $\stackrel{34}{\text {. Detailed }}$ information about meteorological boundary conditions chosen based on standard and design practice recommendations ${ }^{25,33}$ are tabulated in Table 6 . It also provides a summary of all analysis specifications in terms of controlling strategies and loading status utilized in the present study.

75

76


Table 6. Summary of analysis specifications.

\begin{tabular}{|c|c|c|c|}
\hline \multicolumn{4}{|l|}{ Controlling strategies ${ }^{29}$} \\
\hline \multicolumn{2}{|c|}{$\begin{array}{l}\text { Operational modes } \\
\text { - Variable-speed at 3-11.4 m/s, } \\
\text { - Collective blade pitch at } 11.4-25 \mathrm{~m} / \mathrm{s} \text {, } \\
\text { - Zero blade pitch angle, } \\
\text { - Enabled yaw DOF. }\end{array}$} & \multicolumn{2}{|c|}{$\begin{array}{l}\text { Parked modes } \\
\text { - Fixed rotor, } \\
\text { - Feathered blades, } \\
\text { - Zero degree azimuth angle, } \\
\text { - Disabled controllers, } \\
\text { - In place mechanical brakes, } \\
\text { - Disabled generator DOF, } \\
\text { - Enabled yaw DOF. }\end{array}$} \\
\hline Loading status & Aerodynamic & $n^{29}, \underline{30}, \underline{34}$ & Hydrodynamic specification $\underline{29,31}$ \\
\hline Wave-induced only & $\begin{array}{l}\text { - Disabled aer } \\
\text { - Disabled dyr } \\
\text { calculations. }\end{array}$ & $\begin{array}{l}\text { oads, } \\
\text { w wake }\end{array}$ & $\begin{array}{l}\text { - Sea states from Table } 5 \\
\text { - JONSWAP spectrum, } \\
\text { - } \gamma=3.3 \\
\text { - } C_{D}=0.6\end{array}$ \\
\hline Wind-induced only & $\begin{array}{l}\text { - Turbulent wi } \\
\text { - Kaimal turbu } \\
\text { - Normal turb } \\
\text { - Power law m } \\
\text { - Sea states fre } \\
\text { - BEM }{ }^{*} \text { mode } \\
\text { - GDW }{ }^{* *} \text { mod } \\
\text { - Enabled dyn }\end{array}$ & $\begin{array}{l}45 \mathrm{~m} \times 145 \mathrm{~m}), \\
\text { el } 25,3 \underline{33}, \\
2 \underline{25}, \underline{33}, \\
\text { an } 8 \mathrm{~m} / \mathrm{s}, \\
\text { than } 8 \mathrm{~m} / \mathrm{s}, \\
\text { wake. }\end{array}$ & Disabled \\
\hline Wind-wave induced & $\begin{array}{l}\text { - Turbulent wi } \\
\text { - Kaimal turbu } \\
\text { - Normal turb } \\
\text { - Power law m } \\
\text { - Sea states fro } \\
\text { - } \text { BEM }^{*} \text { mode } \\
\text { - GDW } \\
\text { - Enabled dyn }\end{array}$ & $\begin{array}{l}45 \mathrm{~m} \times 145 \mathrm{~m}), \\
\text { el } \underline{25,33}, \\
25, \underline{25}, \\
2 \underline{35}, \\
\text { an } 8 \mathrm{~m} / \mathrm{s}, \\
\text { than } 8 \mathrm{~m} / \mathrm{s}, \\
\text { wake. }\end{array}$ & $\begin{array}{l}\text { - Sea states from Table } 5 \text {, } \\
\text { - JONSWAP spectrum, } \\
-\gamma=3.3 \\
-C_{D}=0.6\end{array}$ \\
\hline
\end{tabular}

\section{Results and discussion}

The dynamic behaviour of a mono-column tension-leg-platform floating wind turbine (i.e., MIT/NREL TLPWT) under operational and survival conditions is investigated through a series of coupled dynamic time-domain analysis using the fully coupled aero-hydro-servo-multi-rigidflexible-body design toolset, NREL-FAST. The time-domain numerical simulations are performed for $4100 \mathrm{sec}$ with time steps equal to $0.0125 \mathrm{sec}$ (sampling frequency of $80 \mathrm{~Hz}$ ). The first $500 \mathrm{sec}$ which corresponds to the transient time interval of responses is eliminated. Consequently, the power spectral as well as statistical characteristics of the results including maximum, minimum, mean, and standard deviation are presented based on the time series from $500 \mathrm{sec}$ to $4100 \mathrm{sec}$. The 
primary loads in the present study are wind and wave with headings fixed at zero degree along with $\mathrm{x}$-axis (see Figure 1) for all cases as well as gravity loads. The current loads is not considered in this analysis. It is to be noted that a set of virtual experiment simulations based on available data ${ }^{15}, \underline{17}$ and current guidelines and codes of practice ${ }^{33}$ showed that the influence of current induced loads on the system in the range of environmental conditions and water depth considered in the present study is negligible and hence is not included in the study. Statistical differences in these trial simulations were less than $1 \%$ for structural components, motions, and mooring tensions with a relatively larger drift motion in the applied loads direction. The spectra of the hub-height wind ve'

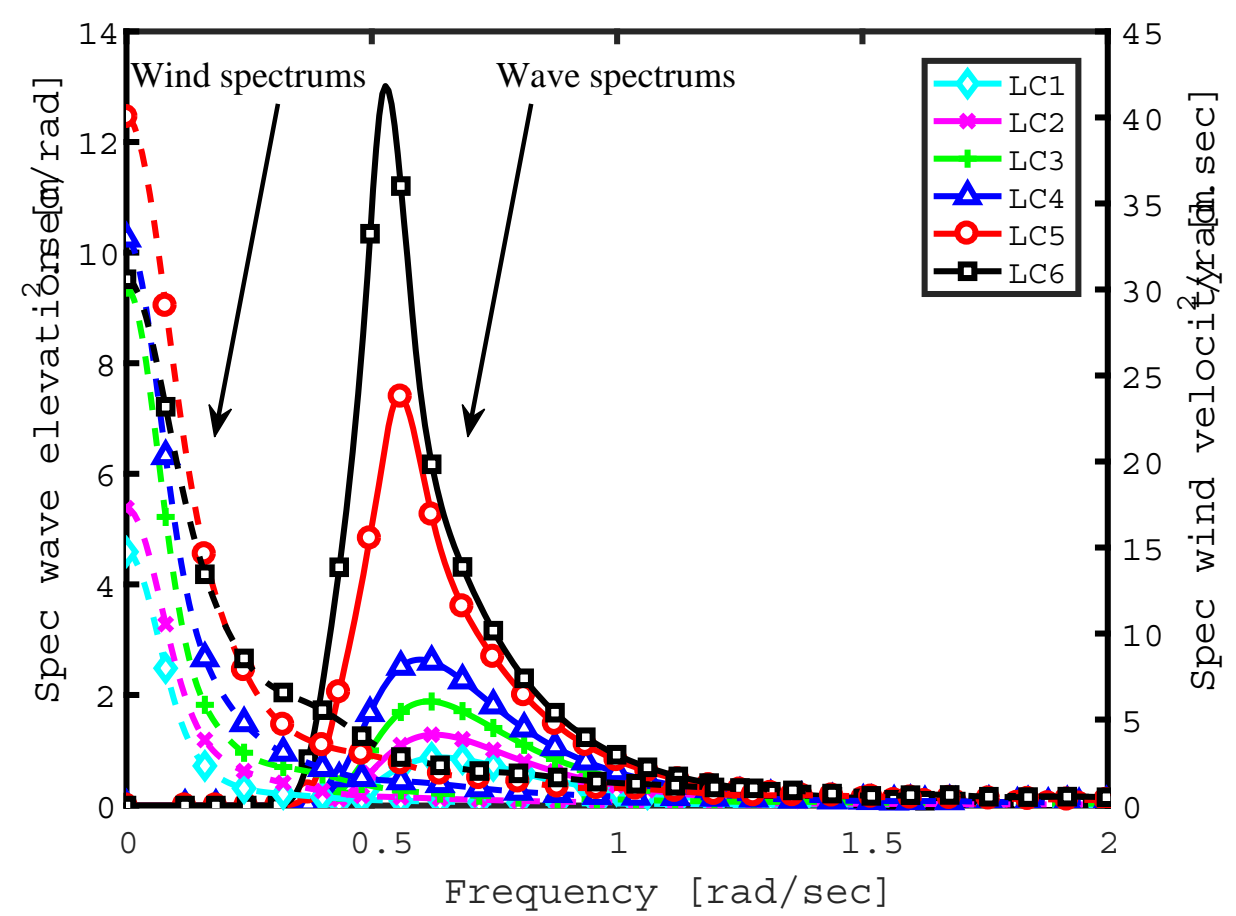

Figure 6. Spectra of hub height wind speed (i.e., dotted lines) and wave elevation (i.e., solid lines) of all specified environmental load cases.

\subsection{Spectral analyses of responses}

In this section, a spectral comparison study is carried out to observe and identify the coupling and dominant effects, the importance of wind load actions on blades, the controlling strategies, the effects of blade rotation, and the influence of tower flexibility on the platform motion and mooring line tension of the floating TLP wind turbine system. The study will be limited to these response variables even though there are other interesting variables which will be assessed in the next section. The results are carried out for a below-rated wind speed loading condition with 
environmental condition as $V=8 \mathrm{~m} / \mathrm{sec}, H_{s}=2.5 \mathrm{~m}$, and $T_{p}=9.8 \mathrm{sec}$ and an over-rated wind speed loading condition with environmental condition as $V=17 \mathrm{~m} / \mathrm{sec}, H_{\mathrm{s}}=4.2 \mathrm{~m}$, and $T_{p}=10.5 \mathrm{sec}$ considering two different elastic and rigid models for tower and three loading combination scenarios: (1) waves-induced only with parked rotor configuration, (2) wind-wavesinduced with parked rotor configuration, and (3) wind-waves-induced with operating rotor configuration. The excitation forces in each of the three scenarios individually are modelled in the same manner.

All the spectrums are obtained and smoothed to capture important peaks and patterns using kernel smoother in $\mathrm{WAFO}^{35}$ with appropriate lag size for the Parzen window function. It should be noted that despite the need for several realizations to calculate an accurate estimation of a Gaussian process spectrum, a smoothed spectra based on a single realization with appropriate duration in most cases can result in a proper estimation of the results and capture the important patterns and fundamental phenomena. Consequently, the spectral analysis of the responses presented here are based on a single one-hour realization for each load case and load combination and do not represent the actual spectrums of one-hour analysis.

Figures 7-10 show the platform surge motion and fairlead tendon tension spectra (the most loaded line, tendon 3 as shown in Figure 1) of the wind turbine system for the aforementioned below- and over-rated load cases (i.e., LC 1 and LC 4). The surge and wave frequencies in the surge response spectrums and pitch and wave frequencies in the tendon tension response spectrums are clearly shown. The additional considerable tension response appeared in the range of $0.5-1$ $\mathrm{rad} / \mathrm{sec}$ are also caused by the nonlinear coupling effect of wave, platform, and mooring line and are a mixed up (i.e., sum and difference frequencies) of wave frequency and surge and pitch natural frequencies. Moreover, the wind-induced low-frequency surge resonant responses in the operational cases of both aforementioned below- and over-rated load cases dominates the surge response as a result of extra wind loading on the system, whilst the pitch-induced high-frequency resonant responses in the parked condition (i.e., waves-induced only) governs the tension response of the system with flexible tower as a result of relative motions of support platform which shows that most of the fluctuation in the tension time histories of both load cases are dominated by pitch motions, as was expected. 
The comparison results also show that the wave frequency responses of all three loading combination scenarios for both elastic and rigid tower models are almost the same which means that the wave frequency part of the responses is affected neither by the aerodynamic damping and controller actions nor the elasticity of tower. Nevertheless, the aerodynamic damping of rotating rotor and tower elasticity show their reduction effects on the wave frequency responses of tendon tensions in the over-rated load case (i.e., higher wind velocity) because of the effects of blade pitch controller actions and relative motions of the system, respectively. The pitch resonant responses, on the other hand, decreased for both rotational and parked rotor configurations compared with the wave-induced only cases due to the combination of aerodynamic damping of rotating rotor and relative motions of support platform whether or not the flexibility of tower is included. The significant reduction of pitch resonant response to the rigid tower responses level in the rotational rotor configuration of over-rated wind speed load case reveals the importance of aerodynamic damping of an operating rotor especially in higher wind speed levels. However, the combination of tower flexibility and relative motions of support platform amplify the resonance amplitudes of pitch in all three scenarios compared with the rigid tower-platform coupling cases as a result of additional moments due to tower disturbance or platform motion. The surge resonant responses with blades rotating rotor configuration also increased considerably because of the extra aerodynamic loading which shows inadequate aerodynamic damping effects to damp the additional excitation forces due to aerodynamic loading. However, despite the considerable increase of the surge resonant response with an operating rotor as a result of tower flexibility in the below-rated load case; these responses not only have lower amplitudes in both rigid and flexible tower models but also the tower elasticity seems to have no influence on this resonant response in over-rated wind speed case which shows that the blade pitch controller actions are very effective in reducing the low-frequencies responses even when the tower elasticity is eliminated from the calculation. Moreover, the pitch natural frequency is shifted slightly down from 1.73 $\mathrm{rad} / \mathrm{sec}$ to $1.33 \mathrm{rad} / \mathrm{sec}$ when the tower elasticity is included. This is because the natural frequencies of a floating wind turbine are functions of the mass distribution and stiffness of the system; and consequently, variation in mass and stiffness distributions of the system due to the tower flexibility actually changes the natural frequencies of the system (i.e., in this case, the pitch natural frequency). It should be stated that the pitch response spectra and nacelle surge acceleration (not 

was exp

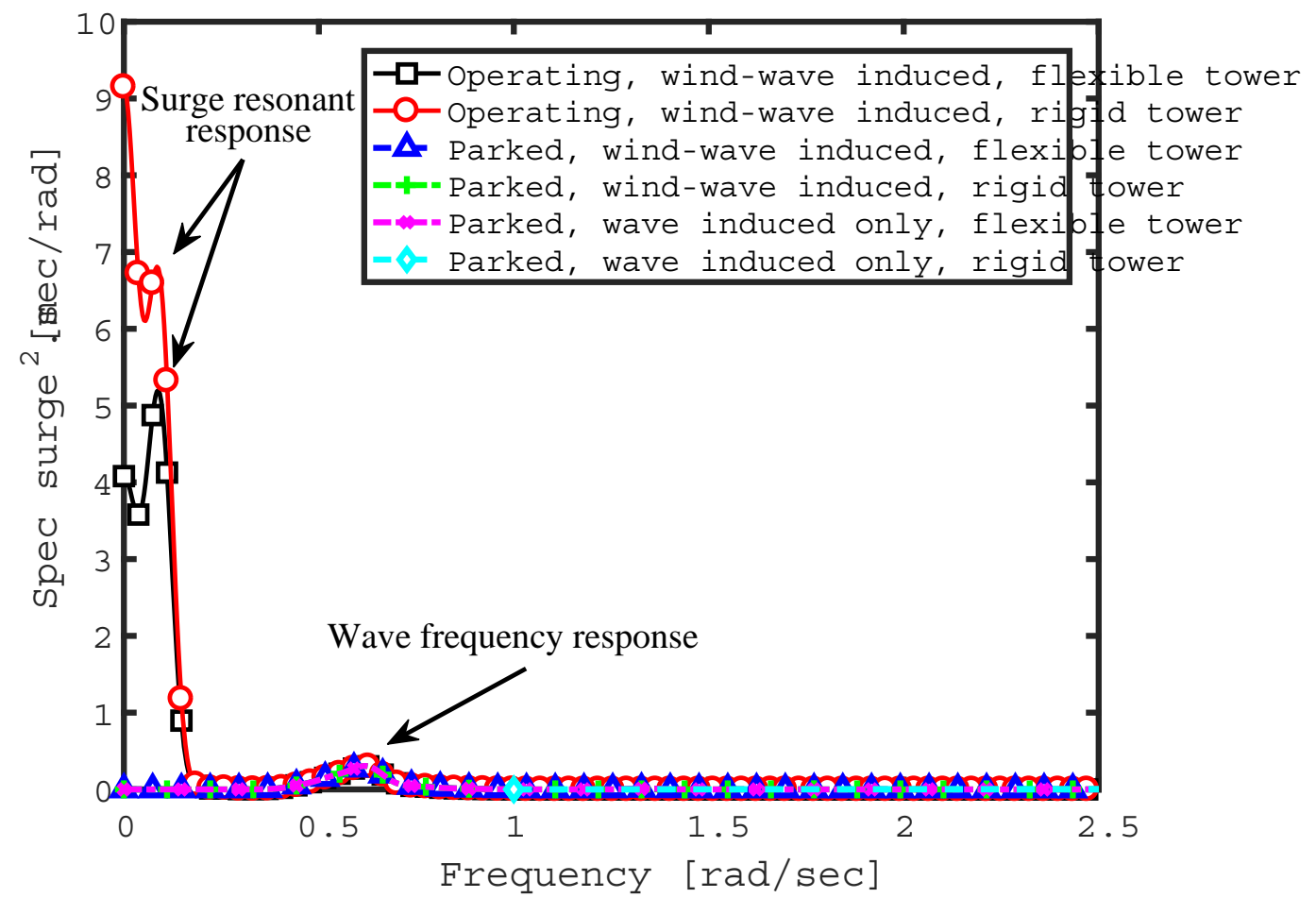

Figure 7. Platform surge motion spectra based on 1hour time domain simulation with flexible and rigid towers and induced by the waves-only and wind-waves for the operating and parked rotors in the below-rated wind condition (LC 


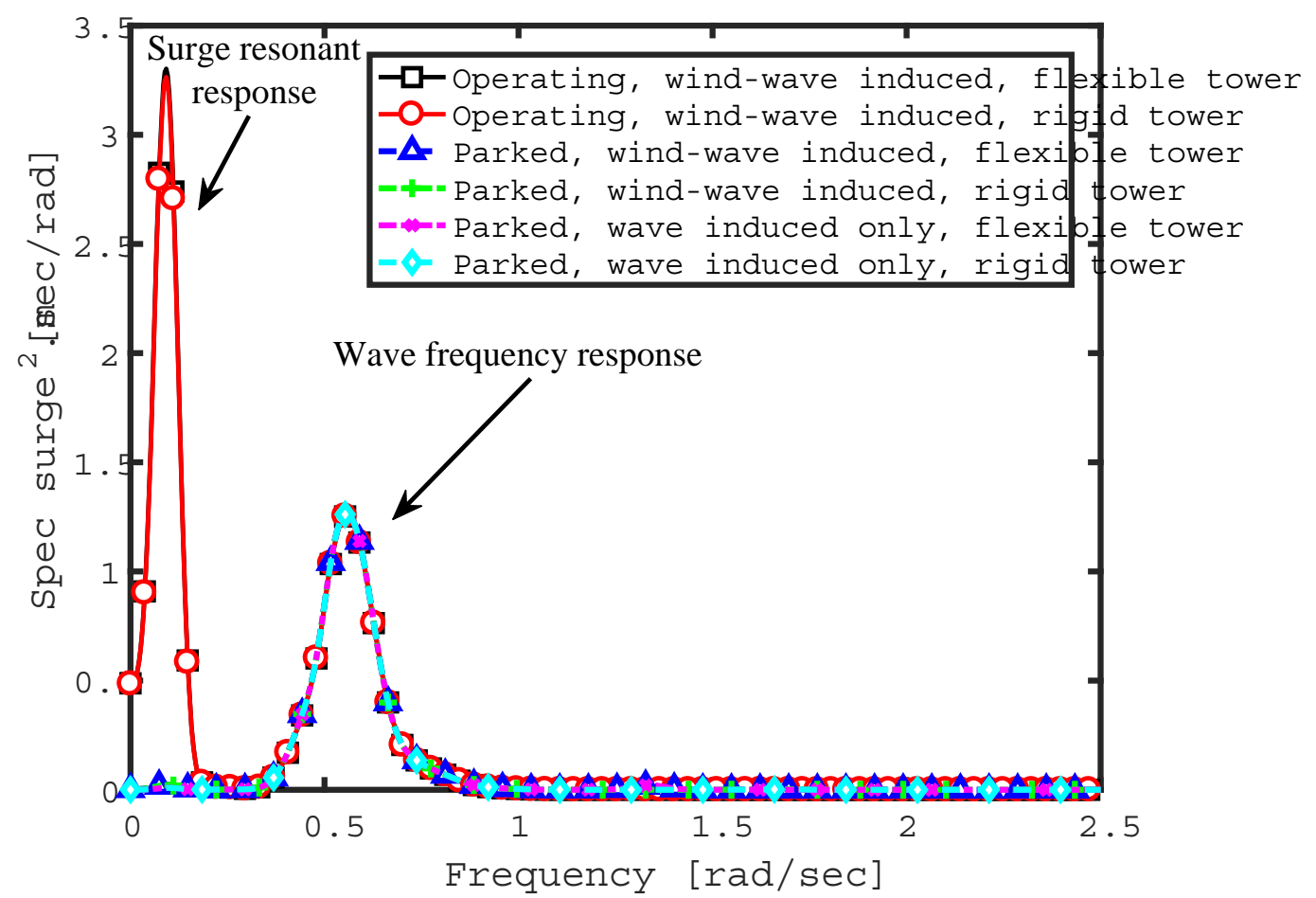

Figure 8. Platform surge motion spectra based on 1hour time domain simulation with flexible and rigid towers and induced by the waves-only and wind-waves for the operating and parked rotors in the over-rated wind condition (LC $4)$.

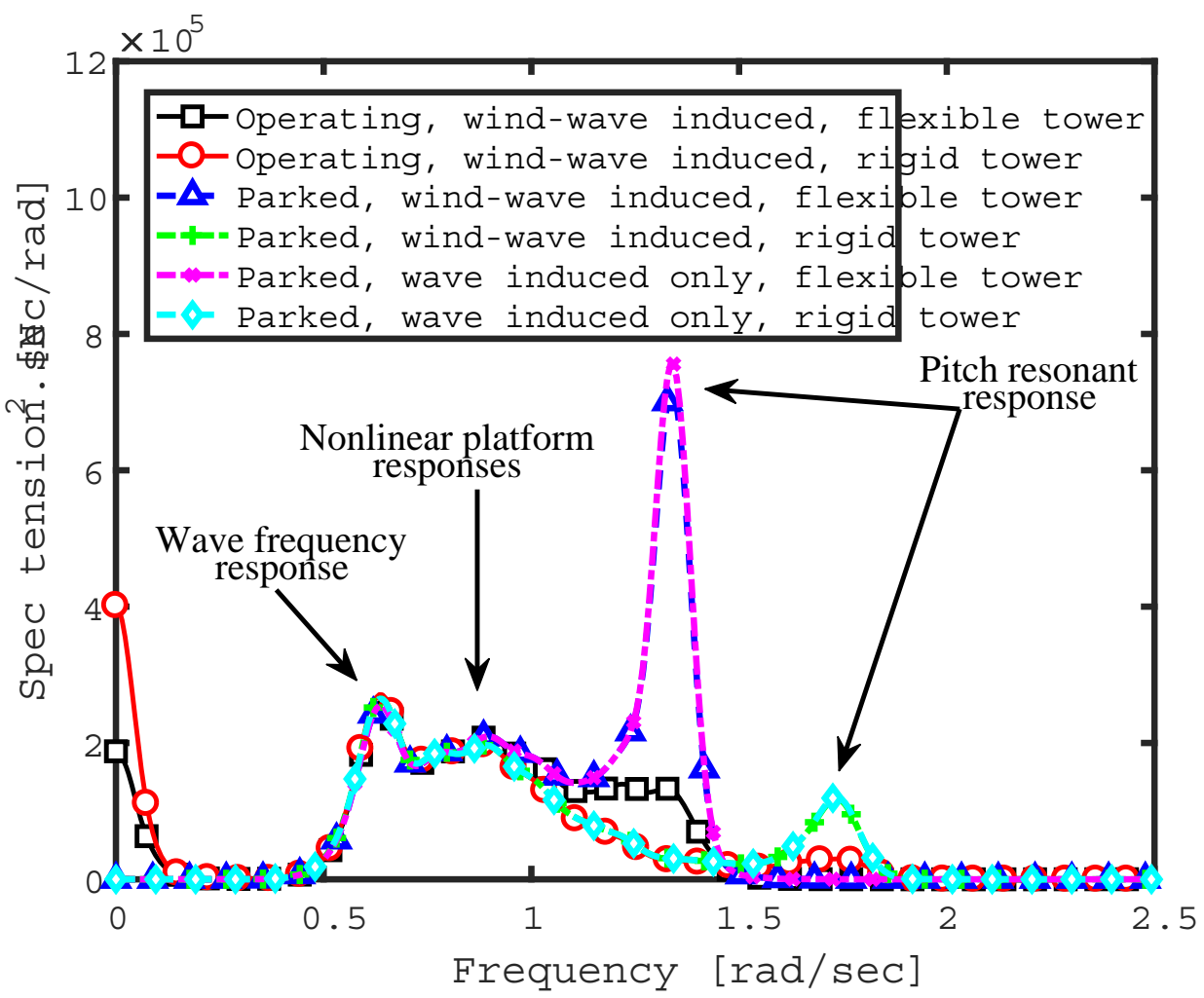


Figure 9. Fairlead mooring line tension spectrum based on 1-hour time domain simulation with flexible and rigid towers and induced by the waves-only and wind-waves for the operating and parked rotors in the below-rated wind condition (LC 1).

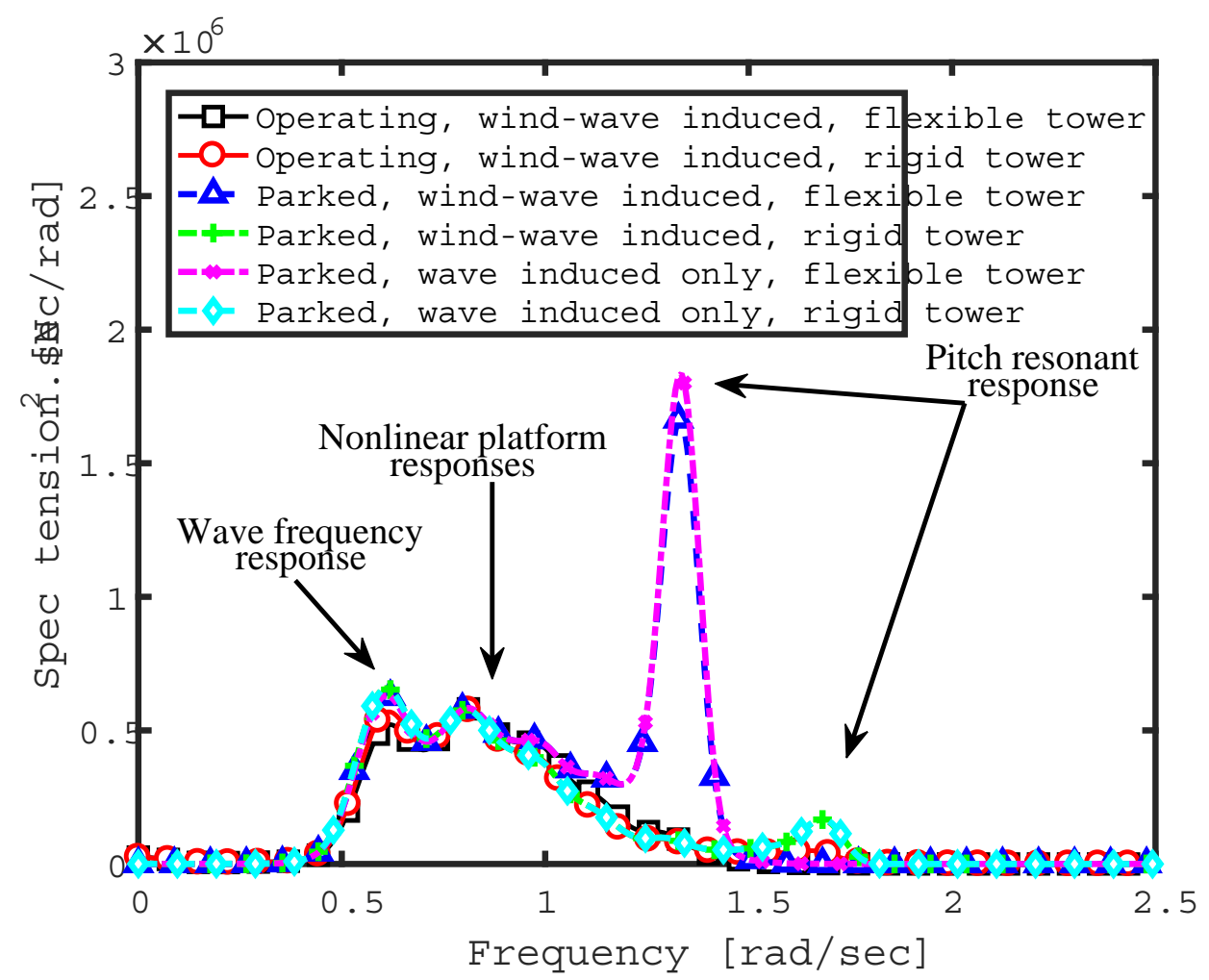

Figure 10. Fairlead mooring line tension spectrum based on 1-hour time domain simulation with flexible and rigid towers and induced by the waves-only and wind-waves for the operating and parked rotors in the over-rated wind condition (LC 4).

\subsection{Statistical analyses of responses}

In this section, a statistical comparison study is carried out to understand the importance of various environmental loading combination, identifying the dominant excitation loads, coupling effects, elasticity of tower, and the influence of controlling strategies on the critical system dynamic responses including thrust force and associated electrical power production, nacelle surge acceleration, structural strength of tower and blades, motion responses, and cables tension are studied as a function of wind speed using the specified load cases in Table 5. It should be noted that the statistical characteristics presented here are based on a single one-hour realization for each load case and load combination and do not represent the actual statistics of one-hour analysis.

\subsubsection{Thrust force and electrical generator power}

Figure 11 shows the statistical characteristics of the thrust force and electrical generator power for two loading combinations (i.e., wind-induced only and combined wind and wave) in different 
load cases. The results show that wave loads do not affect the mean responses very much whether or not the flexibility of tower is included which is because of inherent small dynamic motion characteristics of a tension leg support platform. Nevertheless, the platform motions and tower elasticity cause an increase in the fluctuation of responses especially in the survival conditions when the system is excited by both wind and wave loads. This is in particular more evident in the standard deviation of thrust force in the survival conditions where most of aero dynamical damping effects are eliminated by parking the rotor and featuring the blades and also additional disturbances are induced by extra structural deflections and platform motions. The results also show less than $5 \mathrm{MW}$ power production at the rated wind speed which suggests that some modifications are required for optimization of power production in 5MW NREL. The control strategies are also clear in both mean and standard deviation responses of power production where the controller optimises the rotor rotational speed to maximize the power production for the below-rated wind speeds and the blade pitch position to preserve constant power nroduction for the overrated wind sneeds.
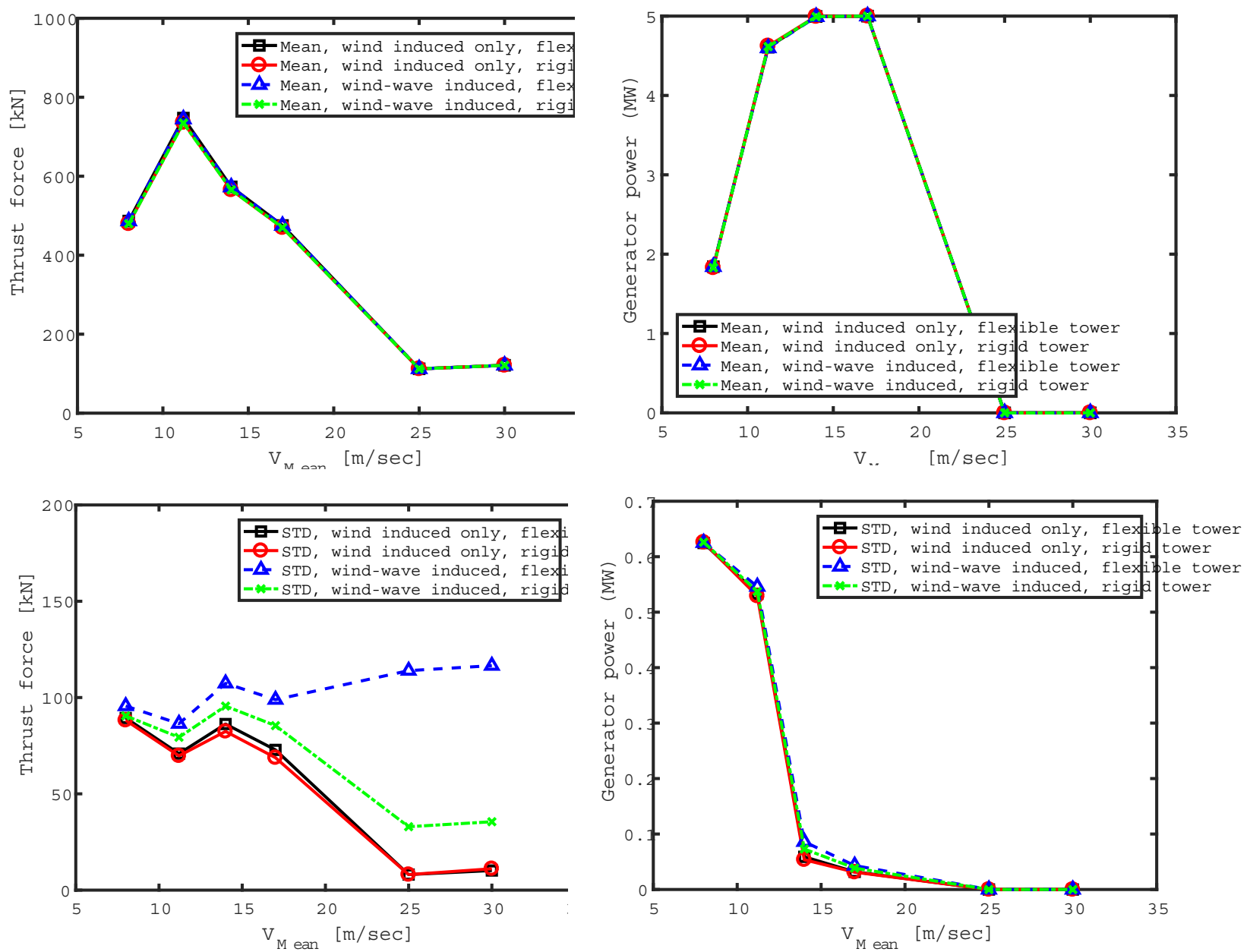
(a)

(b)

Figure 11. Statistical characteristics of the (a) thrust force and (b) electrical generator power.

\subsubsection{Nacelle surge acceleration}

Statistical characteristics of nacelle surge acceleration for all considered load cases considering different load combinations are illustrated in Figure 12. It is seen that the maximum, minimum, and standard deviation of the responses under both operational and survival modes are mainly dominated by the combination of support platform motions and wave loads. The mean of the responses remains fairly constant and is almost the same for different load combinations except for small and negligible differences under survival conditions which are resultant of the aerodynamic damping elimination, extra tower disturbance, and platform motions. The positive aerodynamic damping is also evident in the statistical characteristics of the responses where the floating TLP wind turbine system under combined wind and wave loads has lower responses than the wave-induced only cases (i.e., aerodynamic damping). Moreover, the results show that the maximum responses of nacelle surge acceleration can occur under survival conditions for a floating offshore wind turbine even if the elasticity of tower is excluded, while for a land-based wind turbine it can in fact happen under operational conditions depending on the rated wind speed. The statistical results in terms of pattern are the same for nacelle surge acceleration responses whether or not the elasticity of tower is included. Nevertheless, the main difference is in the magnitude of the values where all the extents are increased in all load cases and combinations. This intensifying effect is in particular obvious for survival conditions, in which the magnitude of the responses are much more higher than the operational cases, while they remains almost the same when the tower elasticity is excluded. The maximum of the responses is less than $1.5 \mathrm{~m} / \mathrm{s}^{2}$ (i.e., 0.15 gravity acceleration) and $4 \mathrm{~m} / \mathrm{s}^{2}$ (i.e., 0.4 gravity acceleration) in operational and survival cases, respectively, which seems to be within acceptable range (i.e., $0.2 \mathrm{~g}-0.3 \mathrm{~g}$ is common practice) and indicates the applicability of this rotor-nacelle assembly for the MIT/NREL TLPWT in such environmental conditions. It can also be seen that the elasticity of tower increases the response up to twice the value of rigid tower cases in the survival conditions, which signifies the importance of elastic structural responses of tower in fatigue lifetime of derive train mechanical components. 

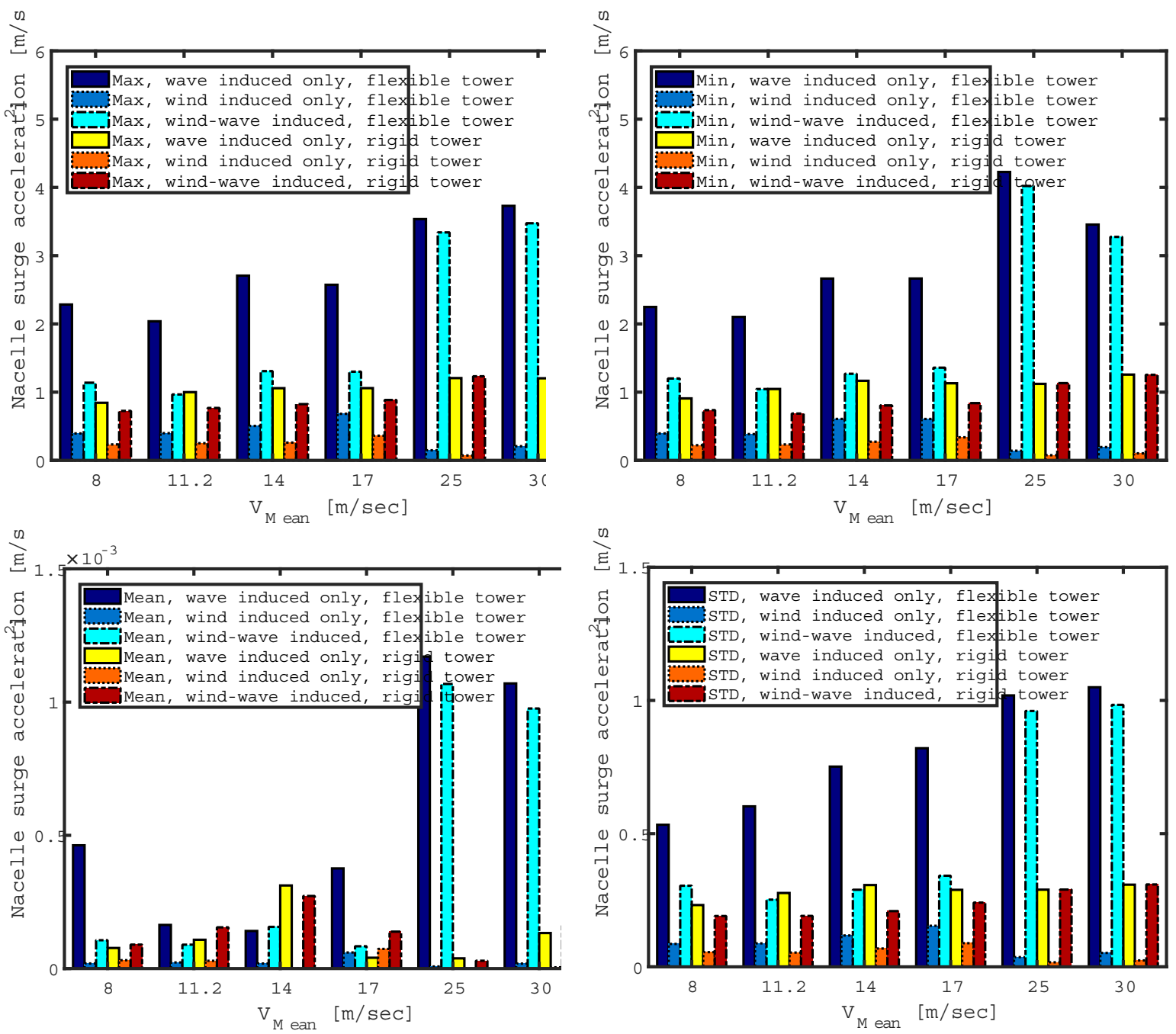

Figure 12. Statistical characteristics of the nacelle surge acceleration.

\subsubsection{Tower and blades}

The statistical characteristics of the tower-base fore-aft and blade root out-of-plane of Blade 1 shear force and bending moment as well as tower-top fore-aft and out-of-plane blade tip deflections of Blade 1 for all the selected operational sea states with two different loading scenarios are shown in Figures 13 and 14, respectively. The maximum and standard deviation responses of the tower (i.e., shear forces and bending moments at the tower-TLP interface and the deflection at the towertop) are mainly induced by the combination of support platform motions and wave loads under both operational and survival conditions. The intensifying effect of the elastic structural responses of tower on the maximum and standard deviation characteristics is also obvious especially when the system is subjected to both wind and wave loadings during the survival conditions. On the contrary, it is seen that neither the wave loads nor tower elasticity have considerable effects on the statistical characteristics of blade out-of-plane responses (i.e., shear forces and bending moments 
at the blade root and the blade tip deflection) as well as the mean responses of tower under operational cases which indicates that the statistical characteristics of blade responses along with mean responses of tower are mainly wind-induced. Nevertheless, small but noticeable differences in the maximum and standard deviation responses of the blade under survival modes show the effects and domination of support platform motions and wave loads, while the mean responses of the blades still are not affected by wave loads. Moreover, the influence of tower flexibility on the statistical characteristics of blade out-of-plane responses and the mean responses of tower in the survival conditions seems to be negligible. Accordingly, it can be concluded that the maximum and standard deviation responses of tower and blades are mainly wave-induced and wind-induced under operational conditions, respectively, and primarily wave-induced under survival condition, whereas the mean responses of the tower and blade in both operational and survival modes is governed by wind loads. The elasticity of tower also influences only the magnitude of the maximum and standard deviation response characteristics of tower.

It is also clear that the maximum and mean responses of tower and blade under operational cases whether the elastic structural responses of tower is accounted in analysis, both start to increase first with increasing wind speed up to the rated wind speed and decrease when the wind speed exceeds the rated wind speed which means they are both affected by the blade pitch controller actions. On the contrary, the standard deviation of responses do not show much variation with wind speeds and remains almost constant with a slight increase by the increase of the wave height in the operational mode which means it is more affected by the wave loads than the blade pitch controller actions. In the survival conditions, on the other hand, at first at the cut-out wind speed, the lower thrust forces along with larger wave loads lead to larger pitch motion (tilt); and consequently, considerable increases occur in the magnitude of the maximum and standard deviation responses of the tower because of the gravitational effects when the system is under both wind and wave loads and tower elasticity is included. The maximum response decreased thereafter because of the large attribution of the tension in the mooring system along with increased hydrodynamic viscous damping forces, whereas the standard deviation increases slightly by the increase of the wave height. Moreover, the results show that the maximum responses of the tower can occur under survival conditions for a floating offshore wind turbine if the elasticity of tower is considered, otherwise it can happen under operational conditions. The maximum responses of blade whether or not the elastic structural characteristics of tower is considered happen under 


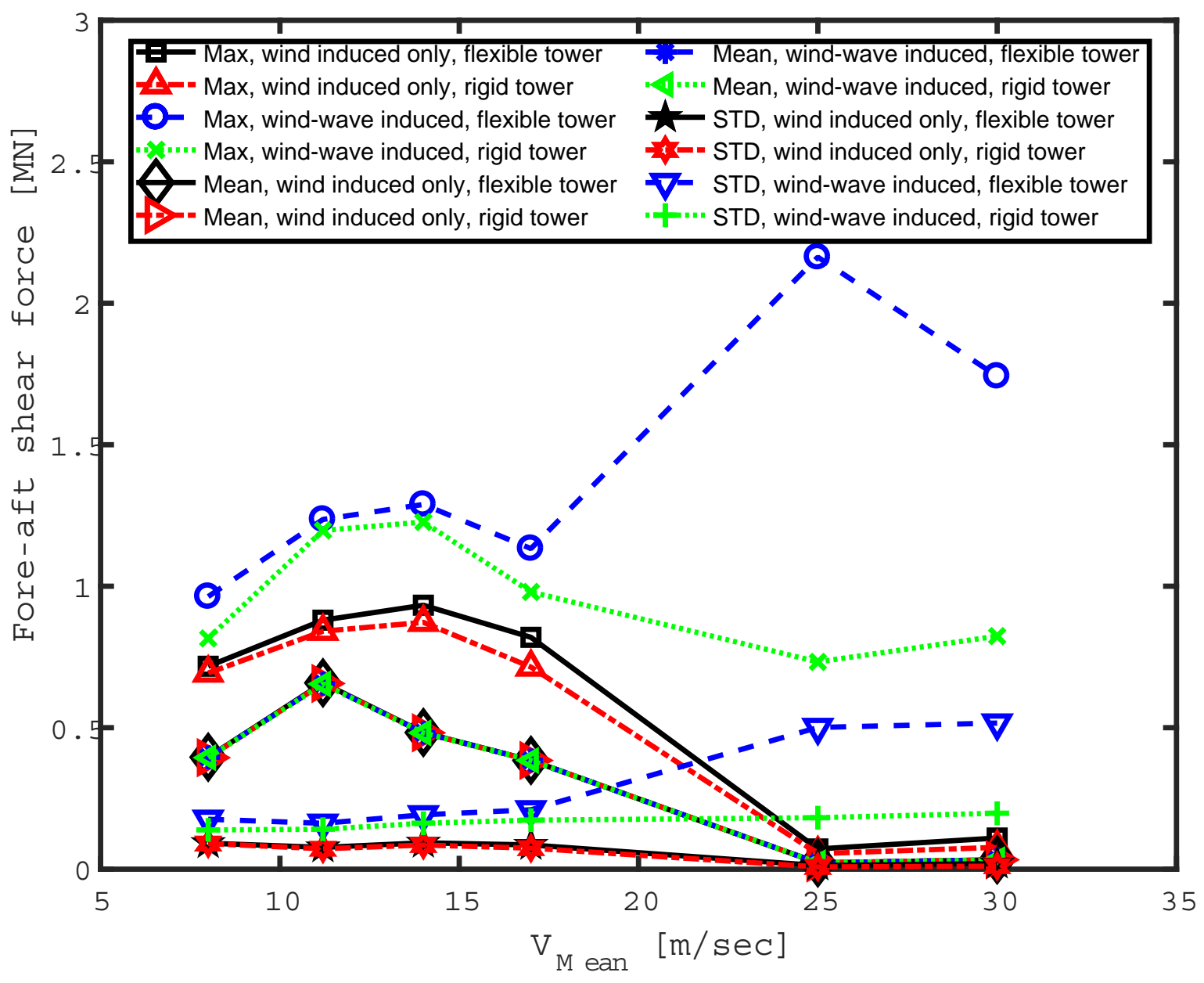




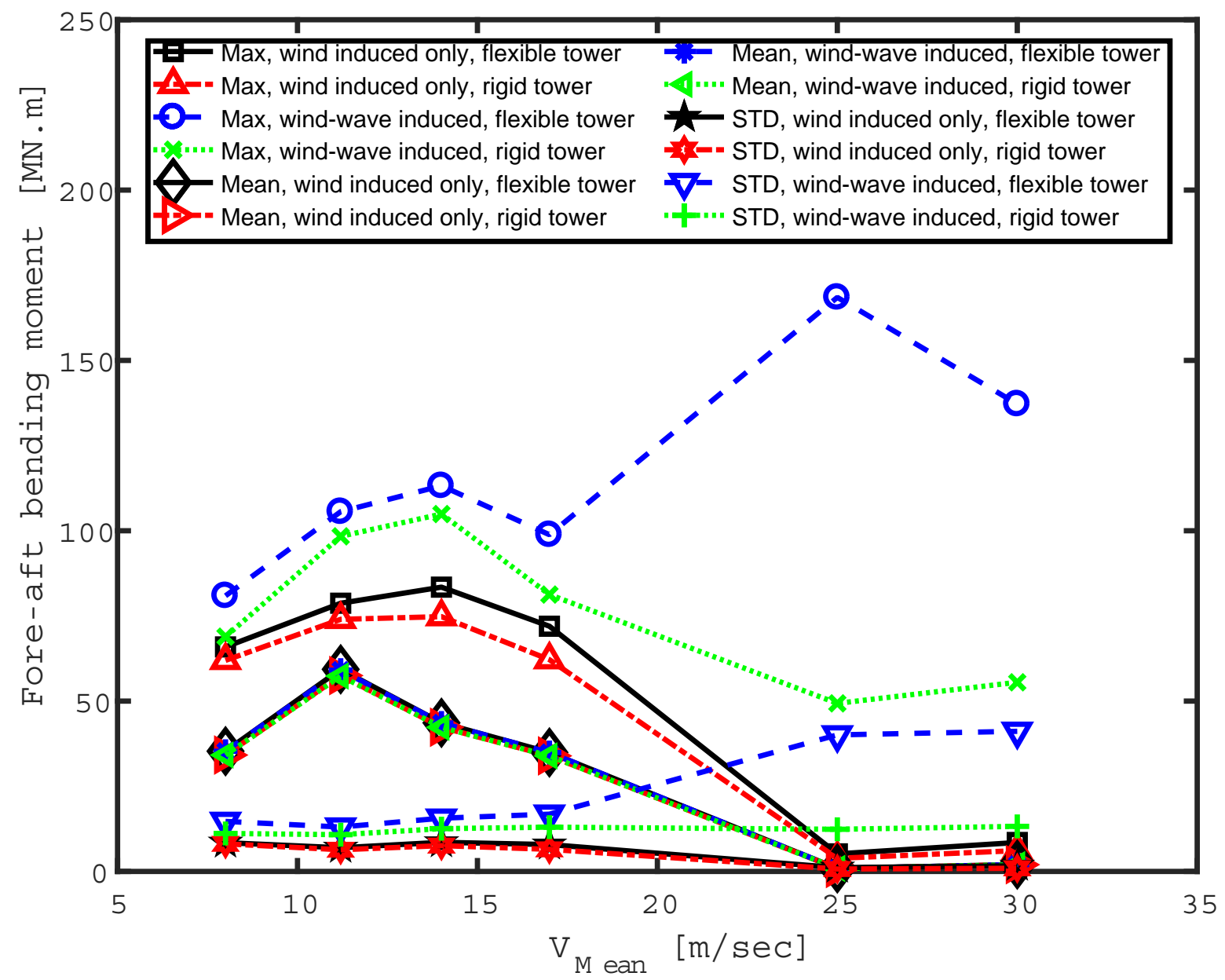

(b) 


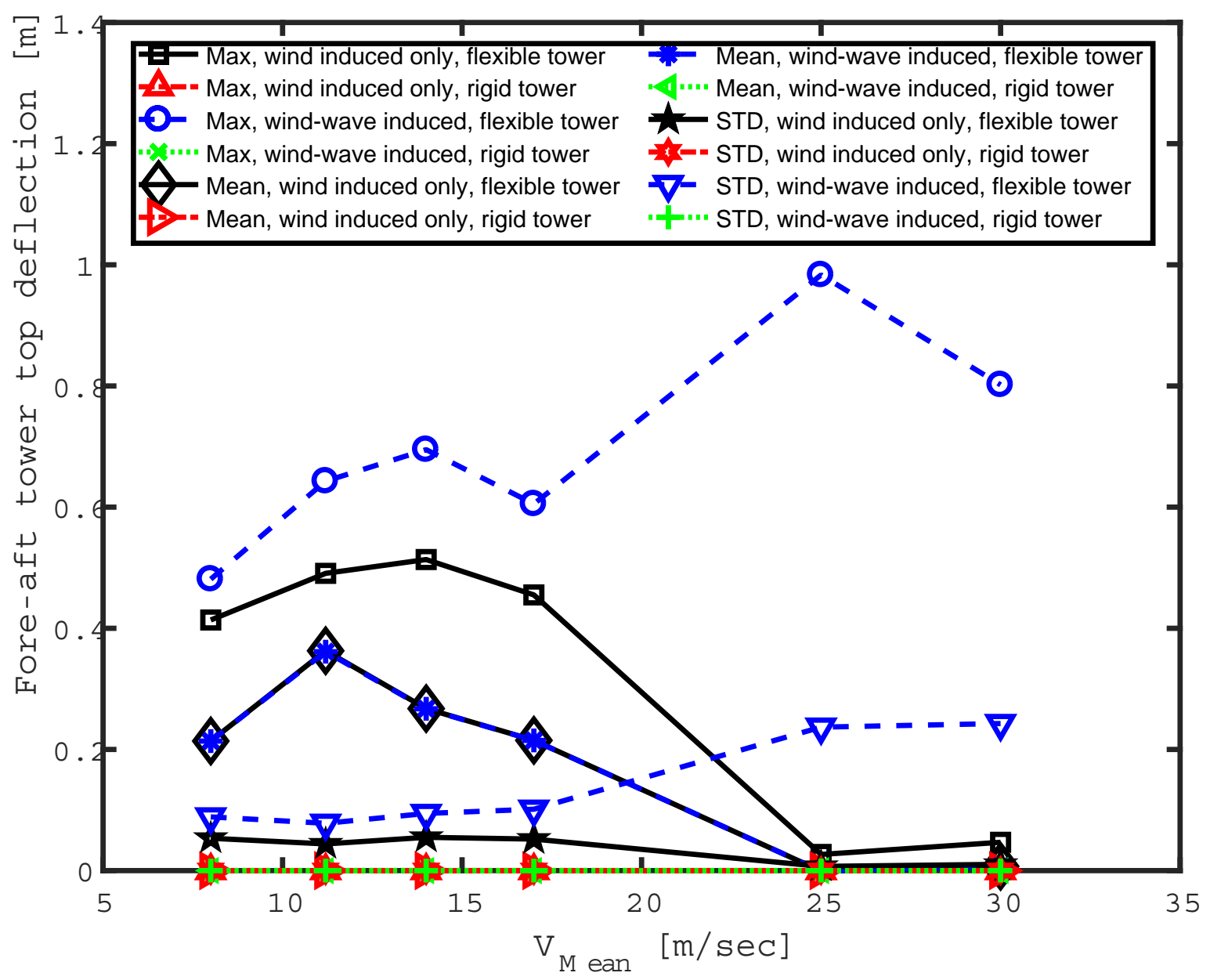

(c)

Figure 13. Statistical characteristics of tower top fore-aft (a) shear force, (b) bending moment, and (c) deflection. 


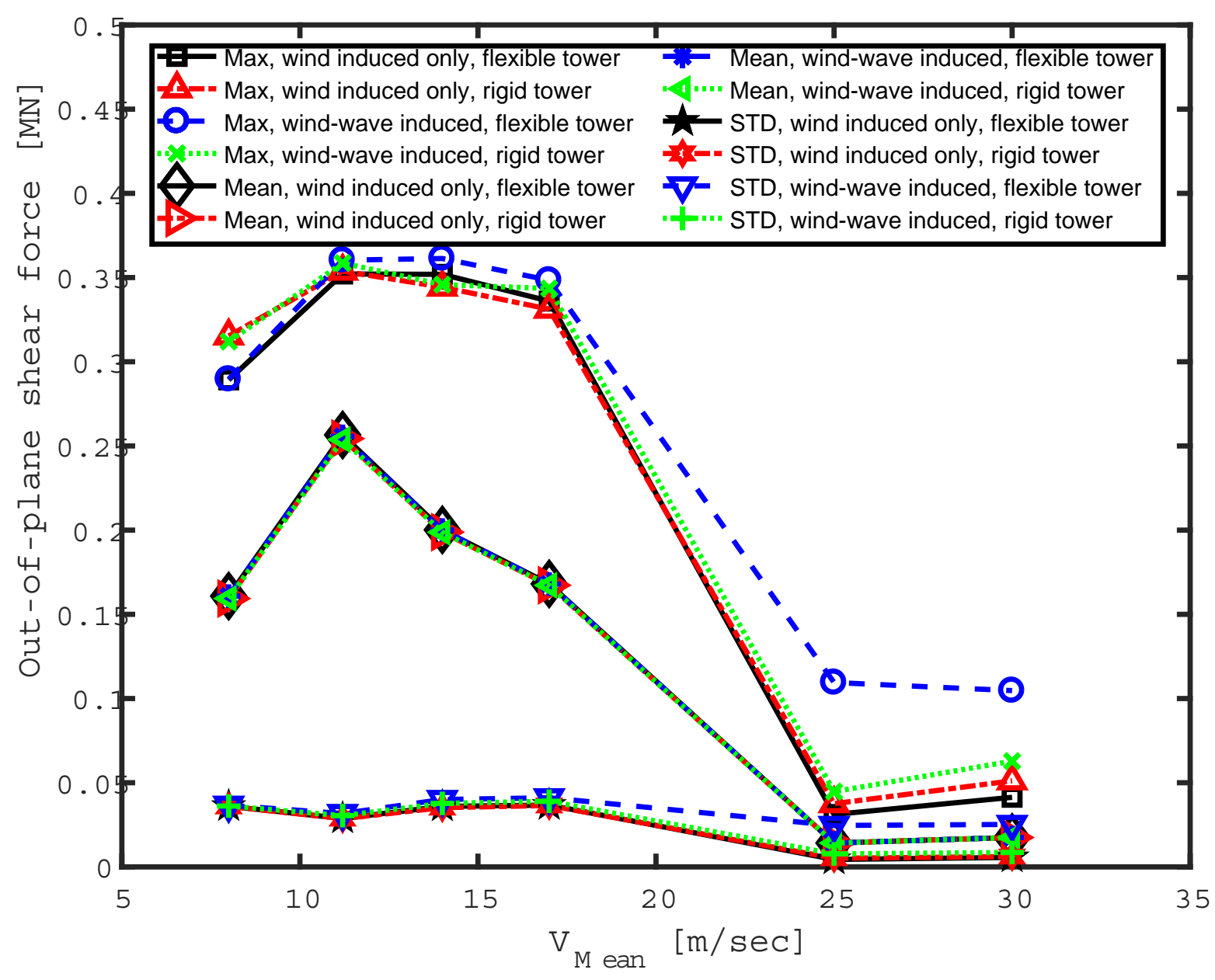




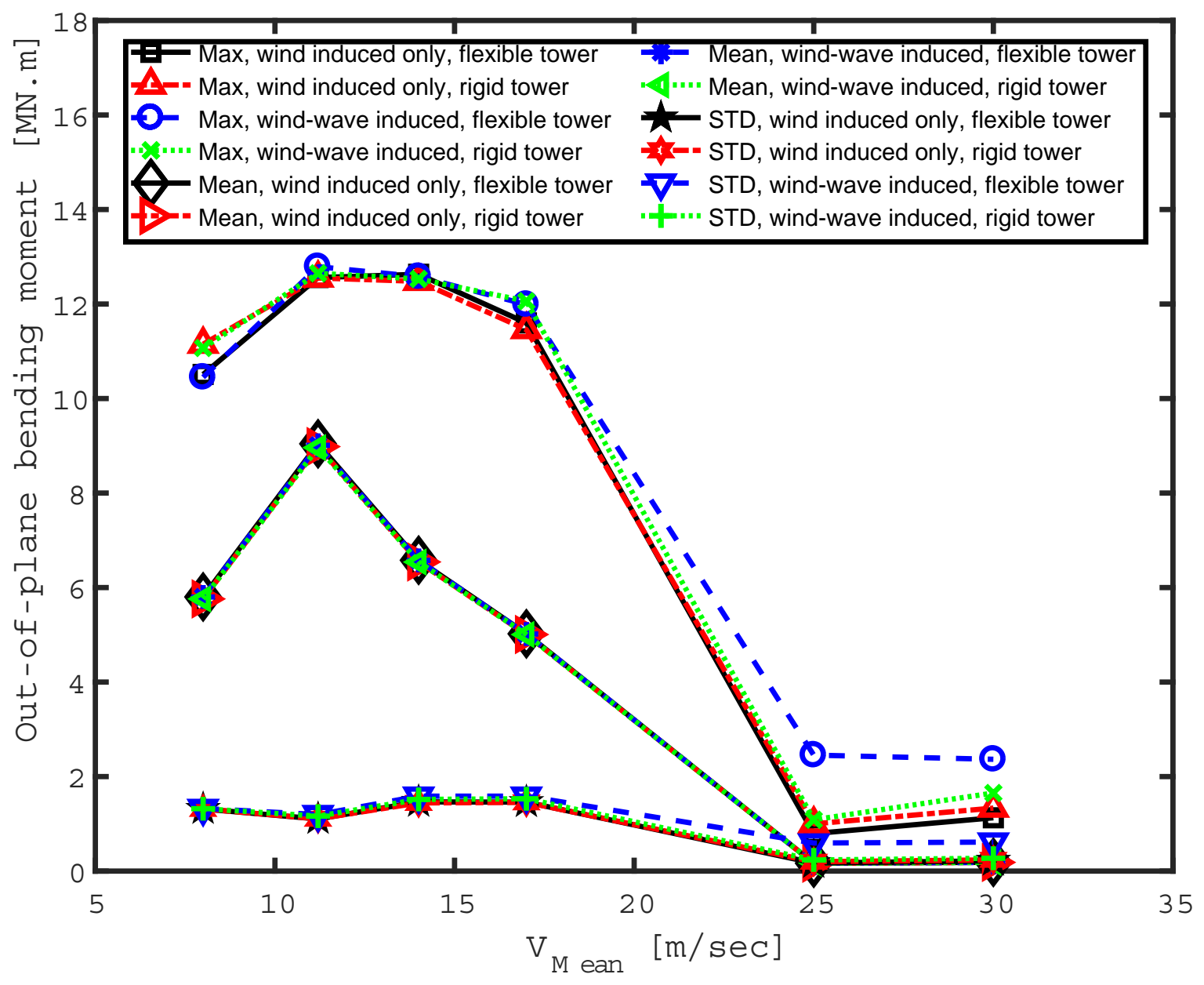




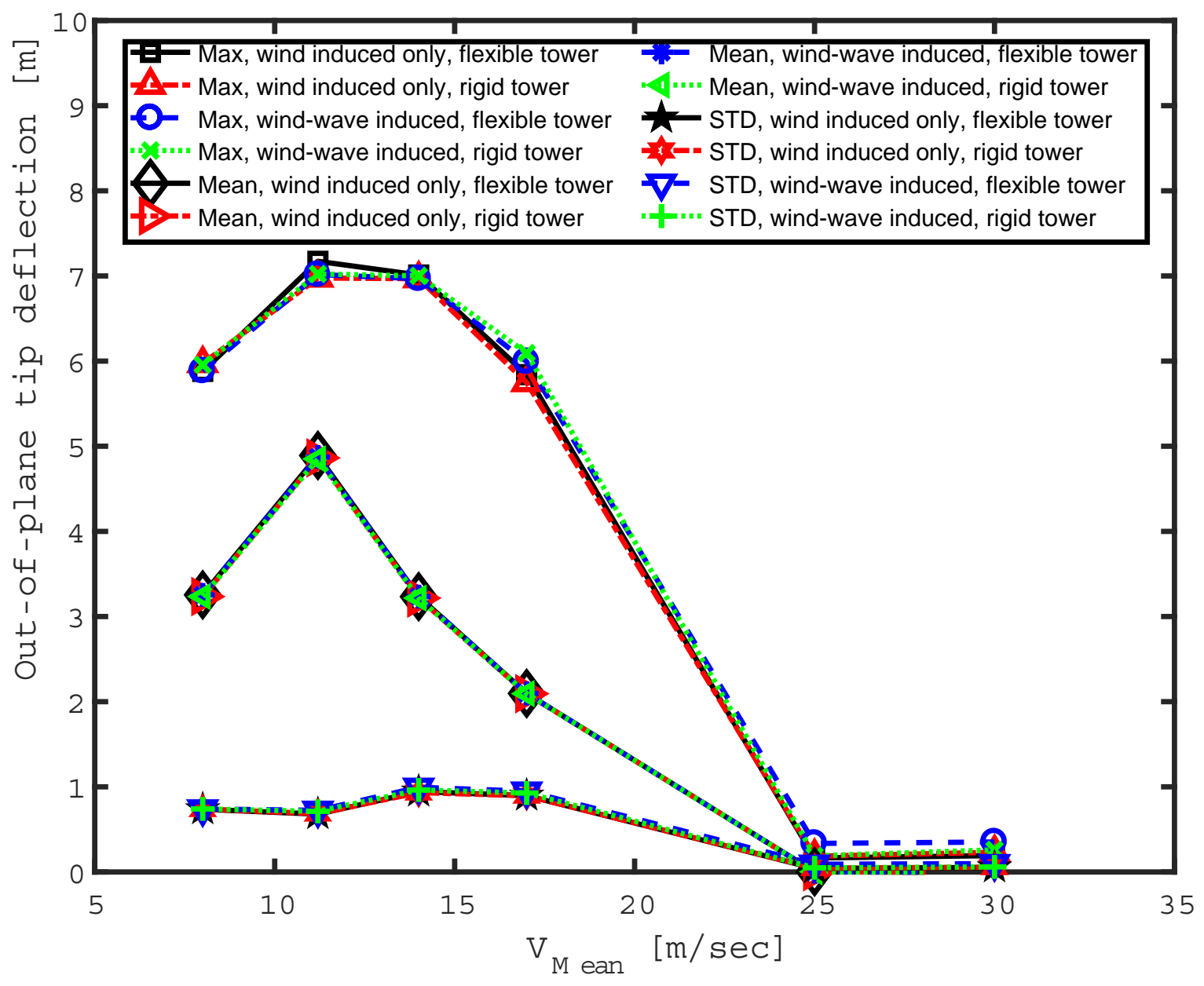

(c)

Figure 14. Statistical characteristics of out-of-plane (a) shear force, (b) bending moment, and (c) deflection of Blade

\subsubsection{Platform motion and mooring line tension}

The platform motions directly affect the tensions in the mooring cables; consequently, the platform displacements and tendon tensions are highly correlated and should have the same trends. Figure 15 represents the maximum responses of the surge and pitch motions of the system as the primary platform modes of motion to have the most significant contributions on the system performance. The results show that in the operational conditions the maximum platform surge and pitch motions are mainly induced by wind loads and wave loads, respectively. In the survival condition, these motions are both dominated by the wave loads, as was expected. From Figure 16, it can also be observed that the maximum and minimum values of platform upwind-side fairlead 
tendon tensions as the critical tendon (the most loaded line, tendon 3 as shown in Figure 1) in both operational and survival modes are mainly wave induced and wind-induced, respectively.

Considering the elastic structural responses of tower, the surge motion responses do not seem to be affected except slight evident increases in survival states, which show not only the suppressing and weakening impacts of rotating blades (i.e., aerodynamic damping) on the increasing effects of tower elasticity but also intensifying influences of tower elastic vibrations on the speed and acceleration of the system shown in combined loadings and more evidently in waveinduced only cases. These results can also be seen more appreciably in pitch motion and maximum and standard deviation of tension responses. Such findings can be anticipated by interpreting the vibrational dynamic characteristics of a floating platform in terms of natural frequencies which is a function of the structural and hydro dynamical mass distribution, stiffness of the system originating from mooring lines, hydrostatic restoring forces, and structural stiffness along with damping arising from aero- and hydro-dynamic loadings. In other words, the effects of loads on the system; and consequently, the reactions and responses of the system can considerably be affect by flexibility/rigidity signifying stiffness and mass distribution of each component as well as coupling considered between system components including platform, mooring system, tower, and RNA. Accordingly, it can be stated that the additional tower elastic vibrations considered in the present study affect the local and global velocity and accelerations of the platform motions and other system components and sub-components, in which then cause extra appreciable variations in inertia forces on the entire system and aerodynamic thrust forces on the blades by changes occurring in the wind speed magnitude through extra rotor plane movements in forward/backward motions of tower top. This can be shown by the use of an equivalent simplified/isolated single degree of freedom structural model for the wind turbine system considering the dominant role of first vibrational mode in the dynamics of using generalized SDOF (GSDOF) idealization theory ${ }^{36}$ along with a simple relation for the total thrust force on the rotor utilized in the blade element momentum (BEM) theory ${ }^{21}$. Such variations could have considerable impacts on wave-induced and resonant responses of the system as can be seen here and presented in previous subsections. Therefore, taking into account the elastic structural responses of system components can play an important role in the safety of tie-down system in the super-structures, design of machinery inside nacelle, ultimate strength, and fatigue-life design perspectives; and consequently, must be considered in design practices. 
The effect of blade pitch controller actions above rated wind speeds is also evident in both motion and mooring line responses where the motion responses both first increase with wind speed up to the rated wind speed and decrease significantly thereafter. Moreover, the effect of wind loads on the pitch motion and mooring line responses in the operational mode is evident from the quite considerable portion of wind loads compared to wave forces. In addition, the positive aerodynamic damping is also evident in the pitch motion responses where the system under combined wind and wave loads has a lower response than the wave-induced only cases. These findings indicate that the extreme value of the responses for a land-based wind turbine occur under the operational conditions depending on the rated wind speed, while the extreme values for a floating wind turbine, whether or not the flexibility of tower in included in the calculations, can happen under survival conditions.

Figure 16 also shows the mean and standard values of the upwind-side tendon tension of the TLP wind turbine at the fairlead position. It can be seen that the mean tension responses is being sensitive to the wind loads, while the wave loads has a greater contribution on the dispersion of tension response about its mean value (i.e., STD). As a consequent, the influence of controller actions on the mean of the responses is very clearer, whereas on the contrary, the standard deviation responses of mooring line top tension increases monotonically by the increase of the wave height in both operational and survival modes which means it is more affected by the wave loads than the blade pitch controller actions. It is also observed that maximum top tension response increased only by $0.35 \%$ after parking the wind turbine, while the standard deviation responses increase by $8.5 \%$ which shows more vulnerability of the mooring cable to the fatigue failures rather than the breaking failures from the axial tensions. These findings would be very important in fatigue life analysis of mooring system. 


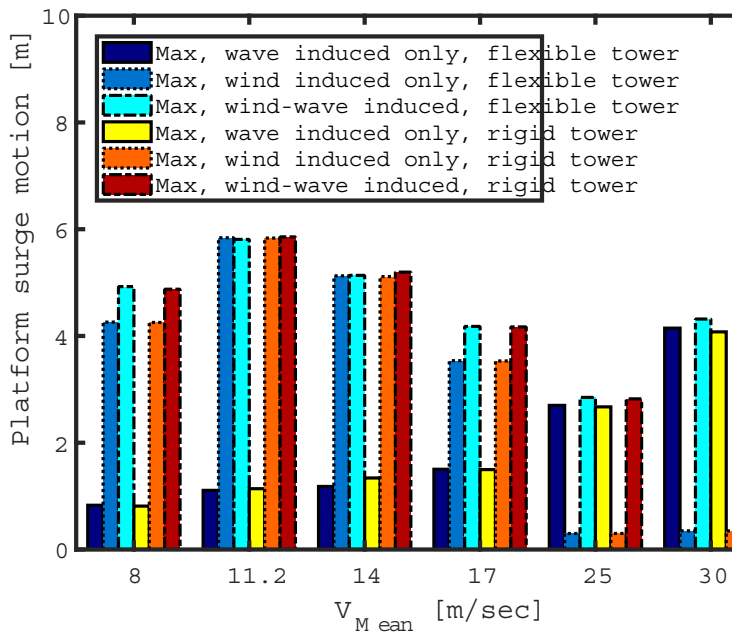

78

782

783

784

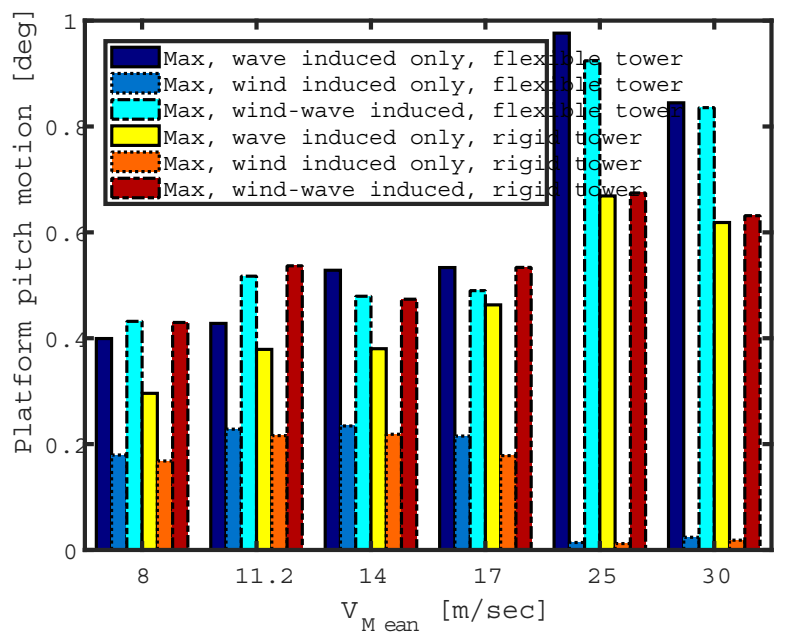

(b)
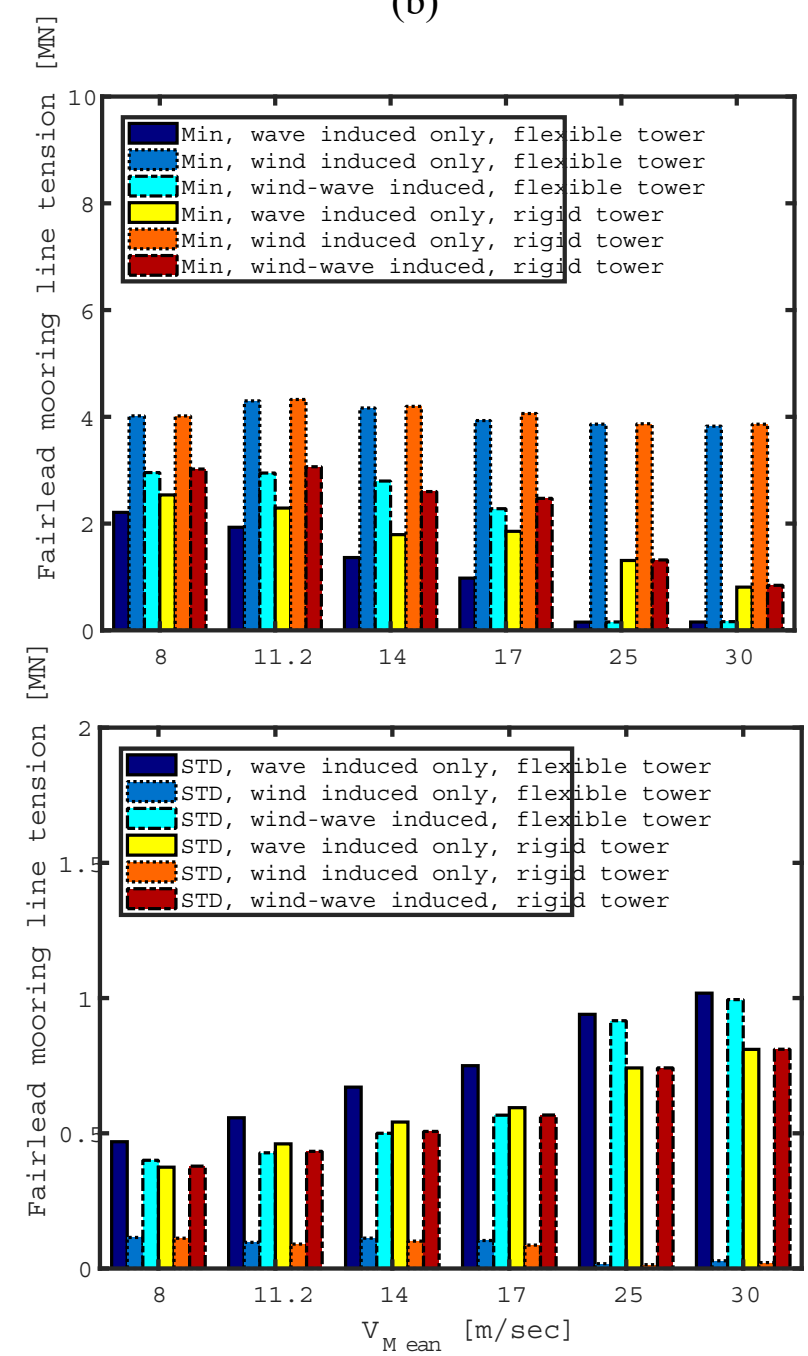

Figure 16. Statistical characteristics of platform upwind-side tendon tension. 


\section{Conclusion}

In this paper, the dynamic behaviour of a mono-column tension-leg-platform floating wind turbine (i.e., MIT/NREL 5-MW tension-leg-platform) under normal and survival conditions were investigated through a series of coupled dynamic analysis using the fully coupled time-domain aero-hydro-servo-multi-rigid-flexible-body design code, NREL-FAST. The loading conditions were chosen based on North Sea environmental condition. Then, for each individual sea state, the critical parameters including the platform motion, the tower, and blades structural responses, mooring system tensions at fairlead as well as the power generation were carried out for performance, stability, and structural evaluation of the system. The effects of external loads coupling actions, rotor and controlling configurations, and platform motion and elastic structural response of tower on the motion, structural strength, cables tension, and power production are studied as well and the dominant excitation loads are identified.

The spectral comparison for below- and over-rated wind speed loading conditions with two different elastic and rigid models for the tower and three loading combination scenarios including wind-waves-induced with parked and operating rotor configurations and waves-induced only showed the following:

- Tower elasticity amplifies and shifts slightly down the high-frequency resonant responses in both below- and over-rated environmental loading conditions, whereas the low-frequency resonant responses are only affected significantly when the rotational speed of the shaft is controlled. On the other hand, the wave-frequency responses are reduced slightly because of the tower flexibility when the wind speed is greater than rated wind speed.

- The aerodynamic damping reduces the pitch resonant responses through the combination of rotational rotor, relative motions of the platform, and extra tower disturbance; whereas it is not adequate to reduce the additional aerodynamic loading which results in greater surge resonant responses in blades rotational rotor configuration. The aerodynamic damping also reduces the wave-frequency responses through the blade pitch controller actions.

The Following conclusions can also be drawn from the statistical characteristics comparison results for the current floating wind turbine:

- Elastic structural responses of tower intensifies the maximum and standard deviation characteristics of the responses especially when the system is subjected to both wind and wave loadings during the survival conditions. 
- The maximum, mean, and standard deviation of responses are all show the same trend for the below-rated wind speeds in which they increase with increasing wind speed due to the control strategy. For the over-rated wind speeds, the maximum and standard deviation responses start with a decrease due to blade pitching effects but increase monotonically thereafter which reveals their sensitivity to wave loads for the higher wave conditions. In contrast, the mean values decrease monotonically after wind speed exceeding the rated value due to blade pitch controller actions.

- Comparison of wave-induced, wind-induced, and wind-waves-induced analyses show that the maximum and standard deviations of the responses are mainly induced by the combination of support platform motions and wave loads and the mean of the responses are mainly wind induced, with the exceptions that the maximum surge motion and maximum and standard deviations of the blade tip out-of-plane deflection in operational cases are dominated by wind loads and standard deviations of the thrust force which is wind induced in both operational an survival modes. The minimum tendon tension and nacelle surge acceleration responses are also shown a sensitive behaviour to the wind loads.

It is to be noted that the discussed conclusions are specific to the TLPWT modelled in this paper and are not intended to be generalized to other TLPWTs. Nevertheless, the provided insight into the dynamic behaviour of the MIT/NREL TLP wind turbine model can help to improve this model for future modifications in different structural components to the initial design for designers in the field of offshore wind industry as well as design standards. The undergoing research focuses on performing a comprehensive study on aerodynamic and hydrodynamic damping, first- and second-order load analysis, and turbulent intensity and misalignment effects in the operational and survival conditions with different loading combination scenarios.

\section{Declaration of conflicting interests}

The authors declare that there is no conflict of interest.

Funding

This research received no specific grant from any funding agency in the public, commercial, or not-for-profit sectors.

\section{References}

1. $\quad$ GWEC. Global Wind Energy. 2016.

2. EIA. International energy outlook 2013 with projections to 2040. 2013. Washington, US. 
3. Thomsen K. Offshore wind: a comprehensive guide to successful offshore wind farm installation. Academic Press, 2014.

4. Collu M and Borg M. 11 - Design of floating offshore wind turbines. In: Ng C and Ran L (eds) Offshore Wind Farms. Woodhead Publishing, 2016, pp.359-385.

5. Niklas K. strength analysis of a large-size supporting structure for an offshore wind turbine. Polish Maritime Research 2017; 24: 156-165.

6. Musial W and Butterfield S. Future for offshore wind energy in the United States. In: EnergyOcean 2004 Conference 2004, pp.4-6.

7. Butterfield S, Musial W, Jonkman J, et al. Engineering challenges for floating offshore wind turbines. In: Copenhagen Offshore Wind Conference, Copenhagen, Denmark 2005, pp.377382. Citeseer.

8. Bachynski EE. Design and dynamic analysis of tension leg platform wind turbines. Norwegian University of Science and Technology (NTNU), Trondheim, Norway, 2014.

9. Matha D. Model development and loads analysis of an offshore wind turbine on a tension leg platform with a comparison to other floating turbine concepts. 2010. National Renewable Energy Laboratory (NREL), Golden, CO. , United States.

10. Henderson AR, Argyriadis K, Nichos J, et al. Offshore wind turbines on TLPs-assessment of floating support structures for offshore wind farms in german waters. In: 10th German wind energy conference, Bremen, Germany 2010.

11. Sharma R, Kim T-W, Sha OP, et al. Issues in offshore platform research - Part 1: Semisubmersibles. International Journal of Naval Architecture and Ocean Engineering 2010; 2: 155170. DOI: https://doi.org/10.2478/IJNAOE-2013-0032.

12. Robertson AN and Jonkman JM. Loads analysis of several offshore floating wind turbine concepts. The Twenty-first International Offshore and Polar Engineering Conference. Maui, Hawaii, USA: International Society of Offshore and Polar Engineers, 2011.

13. Birkeland FM. Numerical simulation of installation of XL monopile for offshore wind turbines. Norwegian University of Science and Technology (NTNU), Trondheim, Norway, , 2016. 14. Karimirad M, Bachynski EE, Berthelsen PA, et al. Comparison of real-time hybrid model testing of a braceless semi-submersible wind turbine and numerical simulations. ASME 36th International Conference on Ocean, Offshore and Arctic Engineering 2017; Volume 10: Ocean Renewable Energy: V010T009A061. DOI: 10.1115/OMAE2017-61121.

15. Jonkman JM. Dynamics modeling and loads analysis of an offshore floating wind turbine. University of Colorado, National Renewable Energy Laboratory (NREL), Golden, CO, United States, 2007.

16. Nielsen FG, Hanson TD and Skaare Br. Integrated dynamic analysis of floating offshore wind turbines. In: 25th International Conference on Offshore Mechanics and Arctic Engineering 2006, pp.671-679. American Society of Mechanical Engineers.

17. Sclavounos P, Lee S, DiPietro J, et al. Floating offshore wind turbines: tension leg platform and taught leg buoy concepts supporting 3-5 MW wind turbines. In: European wind energy conference EWEC 2010, pp.20-23.

18. Withee JE. Fully coupled dynamic analysis of a floating wind turbine system. 2004. Department of Ocean Engineering: Massachusetts Institute of Technology, Cambridge, Massachusetts, USA.

19. Wayman EN, Sclavounos P, Butterfield S, et al. Coupled dynamic modeling of floating wind turbine systems. In: Offshore Technology Conference Texas: Houston, May 1-4 2006, Offshore Technology Conference. 
20. Zhao Y, Yang J, He Y, et al. Dynamic response analysis of a multi-column tension-legtype floating wind turbine under combined wind and wave loading. Journal of Shanghai Jiaotong University (Science) 2016; 21: 103-111.

21. Karimirad M and Moan T. Effect of aerodynamic and hydrodynamic damping on dynamic response of spar type floating wind turbine. In: Proceedings of the EWEC2010, European Wind Energy Conference 20-23 April 2010, Warsaw, Poland, April 20102010.

22. Bae YH. Coupled dynamic analysis of multiple unit floating offshore wind turbine. Texas A\&M University, Texas, United States, 2013.

23. Chen $\mathrm{J}$ and $\mathrm{Hu} \mathrm{Z}$. Experimental investigation of aerodynamic effect-induced dynamic characteristics of an OC4 semi-submersible floating wind turbine. Proceedings of the Institution of Mechanical Engineers, Part M: Journal of Engineering for the Maritime Environment 2017; 232: 19-36. DOI: https://doi.org/10.1177/1475090217706194.

24. IEC61400-1. Wind turbines-Part 1: Design requirements. International Electrotechnical Commission 2005.

25. IEC61400-3. Wind Turbines-Part 3: Design requirements for offshore wind turbines. International Electrotechnical Commission 2009.

26. Shirzadeh R, Devriendt C, Bidakhvidi MA, et al. Experimental and computational damping estimation of an offshore wind turbine on a monopile foundation. Journal of Wind Engineering and Industrial Aerodynamics 2013; 120: 96-106. DOI: https://doi.org/10.1016/i.jweia.2013.07.004.

27. Jonkman J, Butterfield S, Musial W, et al. Definition of a 5-MW reference wind turbine for offshore system development. National Renewable Energy Laboratory (NREL), Golden, CO, Technical Report No NREL/TP-500-38060, United States 2009.

28. Paul B. Kinematics and dynamics of planar machinery. Allyn and Bacon Boston, 1979.

29. Jonkman JM and Buhl Jr ML. FAST user's guide. National Renewable Energy Laboratory (NREL), Golden, CO, Technical Report No NREL/EL-500-38230, United States 2005.

30. Moriarty PJ and Hansen AC. AeroDyn theory manual. National Renewable Energy Laboratory (NREL), Golden, CO, United States 2005.

31. Jonkman J, Robertson A and Hayman G. HydroDyn user's guide and theory manual. National Renewable Energy Laboratory (NREL), Golden, CO, United States 2014.

32. Johannessen K, Meling TS and Hayer S. Joint distribution for wind and waves in the northern north sea. In: The Eleventh International Offshore and Polar Engineering Conference 2001, International Society of Offshore and Polar Engineers.

33. DNVGL-RP-C205. Environmental conditions and environmental loads. Det Norske Veritas group, Norway 2017.

34. Jonkman BJ and Buhl M. TurbSim user's guide. National Renewable Energy Laboratory (NREL), Golden, CO, Technical Report No NREL/EL-500-36970, United States 2004.

35. Brodtkorb PA, Johannesson P, Lindgren G, et al. WAFO-a Matlab toolbox for analysis of random waves and loads. In: The Tenth International Offshore and Polar Engineering Conference 2000, International Society of Offshore and Polar Engineers.

36. Clough RW and Penzien J. Dynamics of structures. Computers \& Structures, Inc, 2003. 